\title{
Resolution of Rise Time in Earthquake Slip Inversions: Effect of Station Spacing and Rupture Velocity
}

\author{
by Surendra Nadh Somala, Jean-Paul Ampuero, and Nadia Lapusta
}

\begin{abstract}
Earthquake finite-source inversions provide us with a window into earthquake dynamics and physics. Unfortunately, rise time, an important source parameter that describes the local slip duration, is still quite poorly resolved. This may be at least partly due to sparsity of currently available seismic networks, which have average sensor spacing of a few tens of kilometers at best. However, next generation observation systems could increase the density of sensing by orders of magnitude. Here, we explore whether such dense networks would improve the resolution of the rise time in idealized scenarios. We consider steady-state pulselike ruptures with spatially uniform slip, rise time, and rupture speed and either Haskell or Yoffe slip-rate function on a vertical strike-slip fault. Synthetic data for various network spacings are generated by forward wave propagation simulations, and then source inversions are carried out using that data. The inversions use a nonparametric linear inversion method that does not impose any restrictions on rupture complexity, rupture velocity, or rise time. We show that rupture velocity is an important factor in determining the rise-time resolution. For sub-Rayleigh rupture speeds, there is a characteristic length related to the decay of the wavefield away from the fault that depends on rupture speed and rise time such that only networks with smaller station spacings can adequately resolve the rise time. For supershear ruptures, the wavefield contains homogeneous $S$ waves the decay of which is much slower, and an adequate resolution of the rise time can be achieved for all station spacings considered in this study (up to few tens of kilometers). Finally, we find that even if dense measurements come at the expense of large noise (e.g., $1 \mathrm{~cm} / \mathrm{s}$ noise for space-based optical systems), the conclusions on the performance of dense networks still hold.
\end{abstract}

\section{Introduction}

Our understanding of the dynamics and physics of earthquakes relies in part on kinematic source inversions that use field observations to infer the time- and space-dependent progression of earthquake source processes. Typically, a fault surface is assumed and discretized into subfaults; the goal of the inversion is to determine time-dependent slip rate of each subfault based on the available data (e.g., Hartzell and Heaton, 1983; Archuleta, 1984). One of the important parameters inferred is the rise time, that is, the time it takes for slip at a particular point on the fault to reach its final value. Accurate estimation of the rise time is quite important for understanding earthquake physics. For example, if the rise time is much shorter than the time required for the rupture to receive healing phases from the fault boundaries, then one may conclude that earthquake ruptures propagate as self-healing slip pulses, as proposed by Heaton (1990). Inferences on fracture energy, the sensitivity of rupture to heterogeneities and the amplitude and frequency-content of near-field ground motions are other aspects of earthquakes that critically depend on rise time. Unfortunately, there are trade-offs between various fault parameters and the rise time is often quite poorly resolved (e.g., Konca et al., 2013).

The resolution of rise time and other parameters by inversions depends both on the available data and on the assumptions made in various inversion procedures. Allowing for variable rupture speeds is typically done in conjunction with assuming the shape of the slip-time function, to reduce the number of free parameters. This parametric approach leads to nonlinear formulations of the inverse problem (Ji et al., 2002; Liu and Archuleta, 2004). Although care is sometimes taken to choose slip-time functions that are similar to those of dynamic rupture modeling, the assumption of the same slip-time function on all fault patches is highly simplified (Shao and Ji, 2012). Formulated in the wavelet domain (Ji et al., 2002) or time domain (Hartzell and Heaton, 1983), such methods rely on global optimization methods such as simulated annealing (Sen and Stoffa, 1991) or genetic algorithms (Sambridge and Drijkoningen, 1992). Another 
class of methods, known as multi-time-window methods (Olson and Apsel, 1982; Hartzell and Heaton, 1983), adopt a nonparametric approach and inverts for slip rate in a certain number of temporal bins, with the timing of rupture constrained by assumed bounds on rupture velocity and rise time. Such methods lead to a linear inverse problem that can be solved by linear least-square optimization (Menke, 1989). Additional constraints such as non-negativity of slip lead to loss of linearity and require specialized methods such as nonnegative least squares (Lawson and Hanson, 1995) to obtain a solution. Smoothness constraints are often incorporated in both parametric and nonparametric approaches to mitigate the intrinsic nonuniqueness of the inverse problem, which is typical in the inference of subsurface parameters from surface data.

Beresnev (2003) demonstrated with examples that source models inverted for the same earthquake by different groups have significant discrepancies in terms of slip distribution and other parameters, sometimes even when the same approach (e.g., Olson and Apsel, 1982, and Hartzell and Heaton, 1983, for 1979 Imperial Valley earthquake) is used by the groups. These discrepancies arise due to subjective decisions made on kinematic parameters and stabilizing constraints.

The inversion procedures are forced to employ a large range of assumptions and constraints in part due to the limited data available, for example, sparse spatial coverage. Seismometers in the best current networks are located tens of kilometers from each other. The source inversion problem with sparse data is severely nonunique, and its regularization requires dramatic assumptions on rupture kinematics. These assumptions are an obstacle to the identification of complex rupture patterns, such as multiple simultaneous rupture fronts and reverse rupture fronts observed in laboratory experiments and dynamic rupture simulations (e.g., Gabriel et al., 2012). Fortunately, much denser seismic networks may soon be available. Block-by-block networks of low-cost microelectro-mechanical system sensors (Clayton et al., 2012) could soon provide ground-motion recordings at every few hundreds of meters in urban areas. Emergent concepts for space-based earthquake observation systems (Michel et al., 2013) could expand such dense coverage to remote areas. These dense observation systems obviously come at a price: their sensitivity or noise level are poorer than in conventional seismic networks. This raises the question of the trade-off between quantity and quality of data for source inversion.

Here, we investigate the role of the network density (or sensor spacing) in the resolvability of earthquake source parameters, focusing on the rise time. The effect of station spacing on inversions has been considered in several studies. Miyatake et al. (1986) and Olson and Anderson (1988) studied this effect by considering a line array of stations perpendicular and parallel to the fault. Saraò et al. (1998) found that stations on the hanging wall facilitate source inversion on dip-slip faults. The case of single-station inversion was considered in Gallovič and Zahradník (2011) to understand the individual contribution of each station. The present study is the first to consider systematically the effect of network spacing in regular 2D networks, including dense networks with a large number of stations that were prohibitively expensive for earlier studies and for certain inversion methods. Owing to advances in computational resources, we are able to extend the station distribution as far as two fault lengths away and still manage to consider station spacings as short as one twentieth of the fault length and one tenth of the fault depth. Although the network aperture may in general also affect the inversion quality, the fixed aperture considered here is typical and covers a significant portion of the focal sphere.

To avoid the effects of various a priori assumptions, we use a modified version of the nonparametric, adjoint inversion method of Somala et al., (unpublished manuscript, 2014), which makes no assumptions on the earthquake source other than a prescribed fault plane. To set up a suitable parameter study and to focus on fundamental aspects of the problem, we consider steady-state pulselike ruptures with spatially uniform slip, rise time, and rupture speed and either Haskell or regularized Yoffe slip-rate function on a vertical strike-slip fault. The rise time and rupture speed are varied from one source model to another. For each source model, we simulate ground velocities. The simulated ground velocities are used as data in our inversion approach, assuming different network densities.

We address the following questions: How narrow are the pulses that can be resolved with a particular network density? How does rupture velocity affect the rise-time assessment? What happens if dense data comes at the expense of higher noise levels?

The rest of this article is organized as follows. In the Theory and Methodology section, we introduce our adjoint inversion method. In the Resolution of Rise Time for Pulselike Ruptures section, quantitative estimates of the resolvability of rise time for various network spacing and rupture speeds are presented. In the Trade-Off between Noise and Network Spacing section, we consider the effects of the additive noise. Our findings are summarized in the Conclusions section.

\section{Theory and Methodology}

\section{Problem Formulation}

We aim at inferring the spatiotemporal distribution of slip velocity on an assumed fault surface from groundmotion data recorded at the Earth's surface. We focus here on strong-motion data, the primary dataset to constrain the detailed time dependency of the rupture process. Other datasets like Global Positioning System or teleseismic waveforms could be included in our source inversion formulation, at the expense of additional complexity in determining the optimal weighting for the different datasets (Sekiguchi et al., 2000; Ide et al., 2005).

The data comprises three-component ground velocity time series $\dot{\mathbf{d}}\left(\mathbf{x}_{r}, t\right)$ recorded at a set of $n$ receiver locations $\mathbf{x}_{r}$ between the initiation of rupture at $t=0$ and the final recording time $t=T$. The source model comprises the 
two-component slip velocity time series $\mathbf{m}(\mathbf{x}, t)$ at all points $\mathbf{x}$ on the fault surface $\Sigma$. The fault geometry is assumed and the fault-normal component of slip is assumed to be zero (shear faulting). We use the term "synthetics" and the notation $\dot{\mathbf{s}}\left(\mathbf{x}_{r}, t, \mathbf{m}\right)$ to denote ground velocities computed at receiver location $\mathbf{x}_{r}$ based on source model $\mathbf{m}$. The synthetic time series and the model parameters are linearly related by a partial differential equation, the seismic-wave equation, or equivalently by a representation theorem (e.g., 3.2 of Aki and Richards, 2002). We concisely write this relation as

$$
\dot{\mathbf{s}}=\mathbf{G m}
$$

in which $\mathbf{G}$ is a linear operator from model space to data space. We seek a model that reproduces the observed wavefield, $\dot{\mathbf{s}}(\mathbf{m}) \approx \dot{\mathbf{d}}$, in a sense that will be made precise below.

Waveform data is usually low-pass filtered prior to earthquake source inversion to downweight the highfrequency components of the wavefield that cannot be well predicted based on the available crustal velocity models, which are usually good for long periods only. We denote the impulse time response of the filter by $h(t)$, its cutoff frequency by $f_{c}$, and the convolution operation between two time series by $*$. We define a cost function $\chi$ that quantifies the misfit between filtered data and filtered synthetics:

$$
\chi(\mathbf{m})=\frac{1}{2} \int_{0}^{T} \sum_{r=1}^{n}\left\|h(t) *\left(\dot{\mathbf{s}}\left(\mathbf{x}_{r}, t, \mathbf{m}\right)-\dot{\mathbf{d}}\left(\mathbf{x}_{r}, t\right)\right)\right\|^{2} d t,
$$

in which $\|\cdot\|$ is the 3D Euclidian norm. Defining a dot product in the data space as $\langle\mathbf{x}, \mathbf{y}\rangle=\int_{0}^{T} \sum_{r=1}^{n}\left(h(t) * \mathbf{x}\left(\mathbf{x}_{r}, t\right)\right)$. $\left(h(t) * \mathbf{y}\left(\mathbf{x}_{r}, t\right)\right) d t$, we concisely write the cost function in terms of the associated data space norm, $\|\cdot\|$ :

$$
\chi(\mathbf{m})=\frac{1}{2}\|\dot{\mathbf{s}}(\mathbf{m})-\dot{\mathbf{d}}\|^{2} .
$$

Our goal is to find the source model $\mathbf{m}$ that minimizes the cost function $\chi$, subject to equation (1). The optimal model in this classical least-squares problem is the solution of the socalled normal equations (Tarantola, 2005):

$$
\mathbf{G}^{\dagger} \mathbf{G m}=\mathbf{G}^{\dagger} \mathbf{d},
$$

in which $\mathbf{G}^{\dagger}$ is the adjoint operator of $\mathbf{G}$, defined as the linear operator from the data space to the model space that satisfies the relation (Tarantola, 2005)

$$
\left\langle\mathbf{d}^{\prime}, \mathbf{G m}^{\prime}\right\rangle=\left\langle\mathbf{G}^{\dagger} \mathbf{d}^{\prime}, \mathbf{m}^{\prime}\right\rangle
$$

for any arbitrary data $\mathbf{d}^{\prime}$ and model $\mathbf{m}^{\prime}$. The right side involves the natural dot product in the model space.

\section{Model Parameterization}

We adopt the multi-time-window approach without any $a$ priori constraints on the hypocenter location, rupture speed, rise time, or shape of the slip-time function. This allows, in principle, to resolve complex scenarios such as fault rerupturing. The slip rate at each subfault is expressed as a linear combination of boxcar temporal basis functions, leading to a linear inverse problem (equation 4). The spatial basis functions are boxcars over each subfault. The slip-rate time windows start from the beginning of an earthquake and extend throughout the duration of the seismograms. The duration of each temporal basis function is the same as the interval at which the seismograms are sampled. The temporal sampling is chosen much smaller than $1 / f_{\mathrm{c}}$ to guarantee discretization errors are insignificant. Spatial sampling, and hence the total number of model parameters, is scenario dependent. Because we do not limit the number of time windows, our scheme can be characterized as the one with "unrestricted multiple time windows." In principle, the model discretization in time is similar to the classical multi-timewindow method introduced by Hartzell and Heaton (1983), but the implementations of that approach are typically limited to about 10 windows (Hartzell and Langer, 1993). Our unrestricted multi-time-window approach allows for time windows to cover the whole duration of the rupture, at all fault locations, unlike other multi-time-window approaches used (Olson and Anderson, 1988; Das and Kostrov, 1990; Gallovič et al., 2009; Gallovič and Zahradník, 2011). Our approach does assume a known fault geometry, as typical in inversions (Hartzell and Heaton, 1983; Olson and Anderson, 1988; Graves and Wald, 2001; Ji et al., 2002).

\section{Green's Functions}

We generate Green's function (GF) to construct $\mathbf{G}$ using the reflectivity method (Fuchs and Müller, 1971; Berman, 1997; Herrmann, 2013). A database of GFs covering all possible distances and azimuths in the densest configuration of stations is computed beforehand and used throughout this study. The same GFs are used both in kinematic forward simulations to generate data as well as in inversions. In other words, we assume that the velocity model is known in complete detail and concentrate on the effect of the network spacing and rupture speed. If the rupture features cannot be resolved with the perfectly known velocity model, then they definitely cannot be resolved with an imperfect model. Hence, our study aims at providing upper bounds on the network density required to resolve given rise times. An approach that does not need calculating GFs for inversion, which is advantageous in 3D heterogeneous velocity models, is described in Somala et al. (unpublished manuscript, 2014).

\section{Inversion Method}

Starting with no prior information (zero initial guess), we use a conjugate gradient (CG) algorithm to minimize the cost function defined in equation (2) (Hestenes and Stiefel, 1952; Fletcher and Reeves, 1964). The CG algorithm is described briefly in the following. The presentation is abstract in the sense that it is valid for both the continuum 
and the discretized forms of the problem. In the continuum formulation, $\mathbf{G}$ and $\mathbf{G}^{\dagger}$ are the forward and adjoint operators, respectively, as previously introduced. In the discrete formulation, $\mathbf{G}$ is a matrix composed of GFs and $\mathbf{G}^{\dagger}$ is its transpose.

1. Assume an initial model $\mathbf{m}^{0}$ (e.g. zero slip rate in space and time) and compute the corresponding synthetics (equation 1), $\mathbf{s}^{0}=\mathbf{G m}^{0}$.

2. Compute the residuals $\mathbf{r}^{0}$ by subtracting the data from the synthetics, $\mathbf{r}^{0}=\mathbf{s}^{0}-\mathbf{d}$.

3. Compute the gradient of the cost function with respect to the model parameters, $\mathrm{g}^{0}=\mathbf{G}^{\dagger} \mathbf{r}^{0}$.

4. Set the search direction, $\mathbf{p}^{0}=-\mathrm{g}^{0}$.

5. Then, for $k=1,2,3,4, \ldots$, repeat the following:

- Compute new synthetics, $\mathbf{s}^{k}=\mathbf{G} \mathbf{p}^{k}$.

- Update the model so that the cost function is minimized along the search direction, $\mathbf{m}^{k+1}=\mathbf{m}^{k}+\alpha \mathbf{p}^{k}$, in which $\alpha=\left\langle\mathbf{r}^{k}, \mathbf{s}^{k}\right\rangle /\left\langle\mathbf{s}^{k}, \mathbf{s}^{k}\right\rangle$.

- Update the residuals, $\mathbf{r}^{k+1}=\mathbf{r}^{k}+\alpha \mathbf{s}^{k}$.

- Compute the new gradient, $\gamma^{k+1}=\mathbf{G}^{\dagger} \mathbf{r}^{k+1}$.

- Update the search direction applying the Polak-Ribiere formula (Polak and Ribière, 1969), $\mathbf{p}^{k+1}=-\gamma^{k+1}+$ $\beta \mathbf{p}^{k}$ in which $\beta=\left\langle\gamma^{k+1}-\gamma^{k}, \gamma^{k+1}\right\rangle /\left\langle\gamma^{k}, \gamma^{k}\right\rangle$.

- If the norm of the new search direction $\mathbf{p}^{k+1}$ is less than a prescribed tolerance (e.g., $10^{-4}$ ) stop. Otherwise, increment the iteration counter, $k \leftarrow k+1$, and go to step 5 a.

Because the approach is constructed based on the adjoint operator $\mathbf{G}^{\dagger}$ and works for the linear formulation in terms of slip rate, we call it the "adjoint linear slip-rate inversion." The method is similar to that used by Gallovič et al. (2009) as both employ adjoint operators and a conjugate gradient solver. However, the work of Gallovič et al. (2009) uses a line fault with no depth resolution and imposes seismic moment and positivity constraints, making their problem nonlinear.

\section{Resolution of Rise Time for Pulselike Ruptures}

\section{Problem Setup}

All rupture scenarios considered in sections hereafter have a fixed moment magnitude of 7.0 and occur on a rectangular vertical fault of length $40 \mathrm{~km}$ and depth $15 \mathrm{~km}$. The rupture reaches the surface. The subfault size is chosen to be $0.5 \mathrm{~km}$. A regular network of seismic stations is deployed on the surface, with fixed spacing and extends as far as two fault lengths away from the fault trace on each side, giving a good surface coverage with aperture of $200 \mathrm{~km}$ and $160 \mathrm{~km}$ in the fault-parallel and fault-normal directions, respectively. The closest stations are located at a distance to the fault trace equal to the spacing between the stations, unless indicated otherwise (Fig. 1).

The cutoff frequency of the low-pass filter is $f_{\mathrm{c}}=1 \mathrm{~Hz}$, and the temporal sampling interval of data and model is $0.1 \mathrm{~s}$. The GF database is accurate up to the Nyquist frequency of $5 \mathrm{~Hz}$. The velocity model used here is a homog-

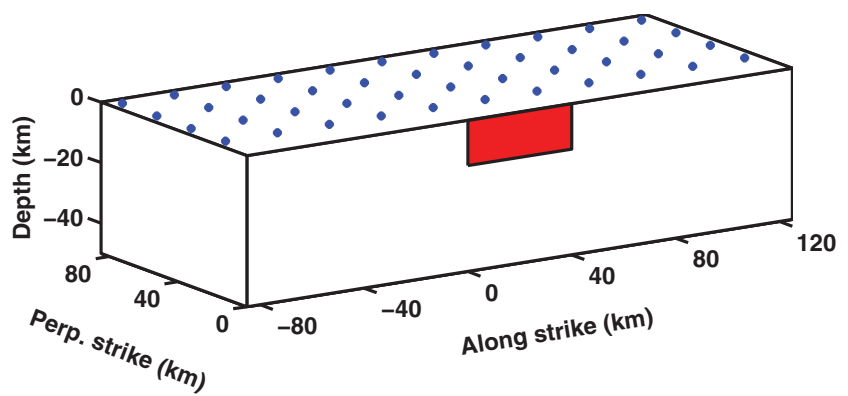

Figure 1. Fault and station network geometry for the rise-time resolution study. The station configuration is shown for the $20 \mathrm{~km}$ station spacing, but various station spacings are considered in this study. For a given spacing, the closest station to the fault is as close as the spacing between stations.

enous half-space with $P$-wave velocity $V_{P}=5.6 \mathrm{~km} / \mathrm{s}, S$ wave velocity $V_{S}=3.2 \mathrm{~km} / \mathrm{s}$, and density $\rho=2.67 \mathrm{~g} / \mathrm{cm}^{3}$.

Our goal is to investigate the rise-time resolution for different station spacings and rupture speeds. For this purpose, we consider a fixed-width slipping pulse of a certain shape propagating unilaterally at a constant speed along the strike of the fault. Two different pulse shapes are considered, boxcar (Haskell, 1969) and regularized Yoffe function (Yoffe, 1951, see also Appendix B). The terms boxcar pulse and Haskell pulse are used interchangeably in the following. Rise times ranging from 0.5 to $4 \mathrm{~s}$ with the increment of $0.5 \mathrm{~s}$ are considered. For a fixed rise time, we also vary rupture velocity to evaluate its influence on the rise-time resolvability. Rupture velocities ranging from 1 to $5 \mathrm{~km} / \mathrm{s}$, with the selected increment of $0.5 \mathrm{~km} / \mathrm{s}$. The slip-time function on a subfault is represented by three parameters: rise time $T_{r}$, rupture velocity $V_{r}$, and total slip $D$. We note that the problem addressed here is linear in slip and prescribed slip is constant everywhere on the fault (nearly $2 \mathrm{~m}$ ), and a parameter study over total slip is not necessary. The different kinds of scenarios considered are summarized in Table 1.

\section{Effect of Network Spacing on Resolving Rise Time} for Subshear Rupture Speeds

Figure 2 shows a representative snapshot of slip rate for inversions of slip pulses with various rise times and network spacings, all with the rupture velocity of $2 \mathrm{~km} / \mathrm{s}$. For the rise time of $1 \mathrm{~s}$, only the densest station configuration, with the spacing of $2 \mathrm{~km}$, shows a spatial pattern of slip rate that resembles the input slip rate. As the spacing between stations increases, the slip pulse smears out over a region wider than the input pulse width, and peak slip velocity is underestimated. As the station spacing gets as coarse as $40 \mathrm{~km}$, there is barely any sign of the pulse. The number of iterations required to stop the conjugate gradient algorithm is presented in Appendix A for the case with $2 \mathrm{~km} / \mathrm{s}$ rupture velocity and $1 \mathrm{~s}$ rise time, by considering the normalized errors in model space and data space. Appendix A also considers the differences between the inverted models and the actual source, to 

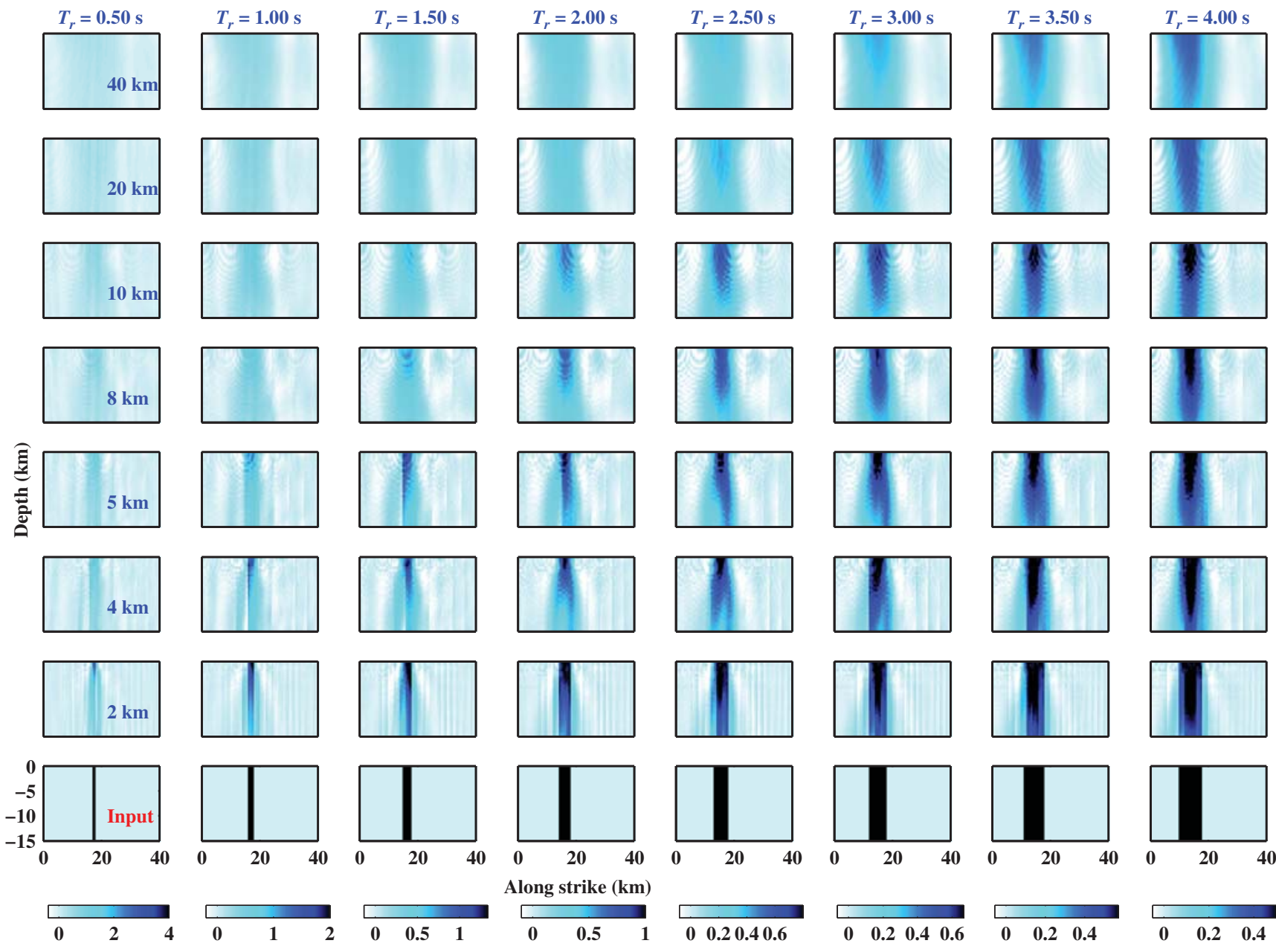

Along strike (km)
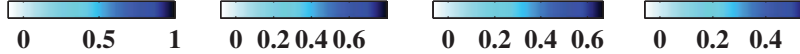

$\begin{array}{lll}0 & 0.2 & 0.4\end{array}$

Figure 2. Representative slip-rate snapshots for the input (bottom row) and inverted source models of Haskell pulses with different rise times propagating at the subshear rupture speed of $V_{r}=2 \mathrm{~km} / \mathrm{s}$. Upper rows show inversions for different network spacings, from 40 to $2 \mathrm{~km}$. Columns correspond to different rise times, from 0.5 to $4 \mathrm{~s}$. Coarser networks cannot resolve shorter rise times.

understand to what extent the spatiotemporal evolution of the model can be retrieved. Changing the pulse shape from boxcar to Yoffe has little effect on the resolution in comparison to the input (Appendix B).
We also consider a rise time of $0.5 \mathrm{~s}$, but its resolution is poor, as expected, because one cannot fairly represent rise times that short while using a filter with the cutoff frequency of $1 \mathrm{~Hz}$. Filters with the higher cutoff frequency cannot be

Table 1

Summary of Kinematic Rupture Scenarios Used for Inversions

\begin{tabular}{|c|c|c|c|c|}
\hline Network Spacing (km) & $\begin{array}{c}\text { Haskell } \\
\left(V_{r}=2 \mathrm{~km} / \mathrm{s}\right) \\
\text { Figures } 2 \text { and } 4\end{array}$ & $\begin{array}{c}\text { Yoffe } \\
\left(V_{r}=2 \text { and } 5 \mathrm{~km} / \mathrm{s}\right) \\
\text { Figures } 22 \text { and } 23\end{array}$ & $\begin{array}{c}\text { Haskell } \\
\left(T_{r}=1 \mathrm{~s}\right) \\
\text { Figures } 6 \text { and } 7\end{array}$ & $\begin{array}{l}\text { Haskell Scenarios with Noise } \\
\left(T_{r}=1 \mathrm{~s}\right) \\
\text { Figures } 11 \text { and } 12\end{array}$ \\
\hline 2 & $T_{r}=0.5-4 \mathrm{~s}$ & $T_{r}=0.5-4 \mathrm{~s}$ & $V_{r}=1-5 \mathrm{~km} / \mathrm{s}$ & $\begin{array}{c}1 \mathrm{~cm} / \mathrm{s} \text { noise } \\
V_{r}=2 \mathrm{~km} / \mathrm{s} \text { and } V_{r}=3 \mathrm{~km} / \mathrm{s}\end{array}$ \\
\hline 4 & $T_{r}=0.5-4 \mathrm{~s}$ & $T_{r}=0.5-4 \mathrm{~s}$ & $V_{r}=1-5 \mathrm{~km} / \mathrm{s}$ & \\
\hline 5 & $T_{r}=0.5-4 \mathrm{~s}$ & $T_{r}=0.5-4 \mathrm{~s}$ & $V_{r}=1-5 \mathrm{~km} / \mathrm{s}$ & \\
\hline 8 & $T_{r}=0.5-4 \mathrm{~s}$ & $T_{r}=0.5-4 \mathrm{~s}$ & $V_{r}=1-5 \mathrm{~km} / \mathrm{s}$ & \\
\hline 10 & $T_{r}=0.5-4 \mathrm{~s}$ & $T_{r}=0.5-4 \mathrm{~s}$ & $V_{r}=1-5 \mathrm{~km} / \mathrm{s}$ & \\
\hline 20 & $T_{r}=0.5-4 \mathrm{~s}$ & $T_{r}=0.5-4 \mathrm{~s}$ & $V_{r}=1-5 \mathrm{~km} / \mathrm{s}$ & $0 \mathrm{~cm} / \mathrm{s}$ noise \\
\hline 40 & $T_{r}=0.5-4 \mathrm{~s}$ & $T_{r}=0.5-4 \mathrm{~s}$ & $V_{r}=1-5 \mathrm{~km} / \mathrm{s}$ & $V_{r}=2 \mathrm{~km} / \mathrm{s}$ and $V_{r}=3 \mathrm{~km} / \mathrm{s}$ \\
\hline
\end{tabular}

Cases with Yoffe and Haskell pulses are both tested for various rise times $T_{r}$, rupture speeds $V_{r}$, and network spacings as indicated. 


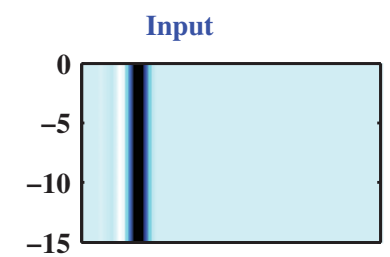

$20 \mathrm{~km}$ network
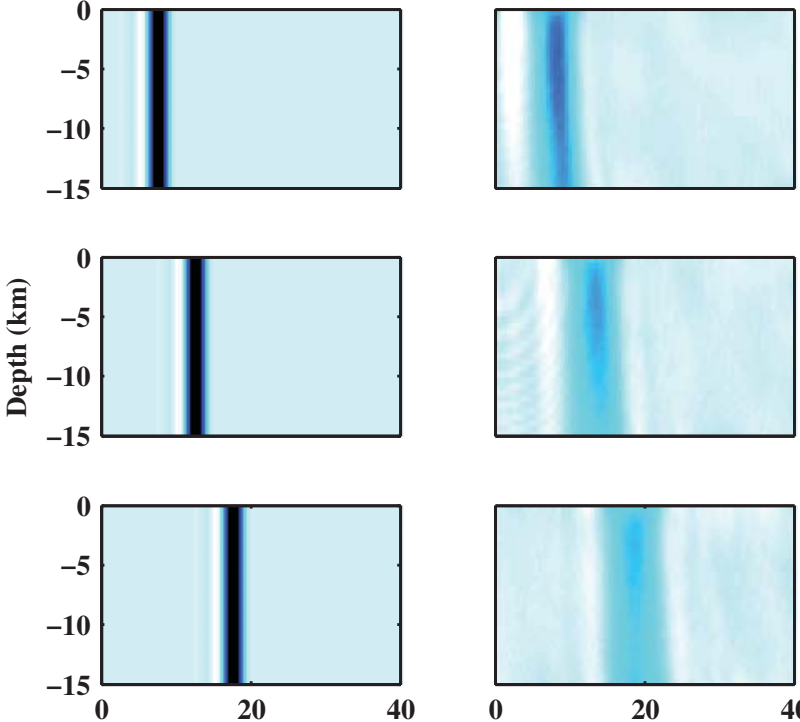
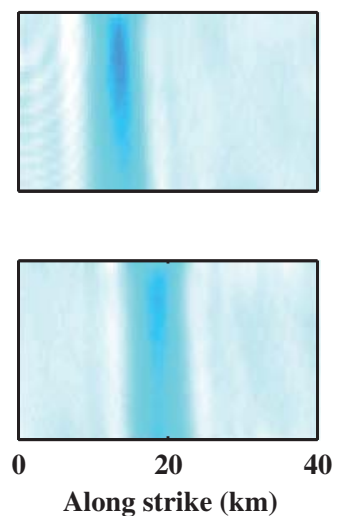

$4 \mathrm{~km}$ network
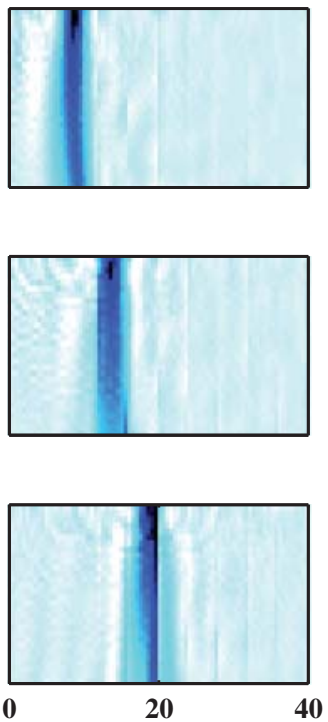

$20 \mathrm{~km}$ network

closest station $4 \mathrm{~km}$
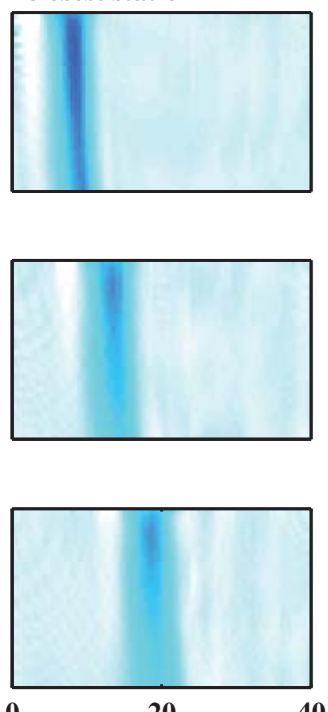

40

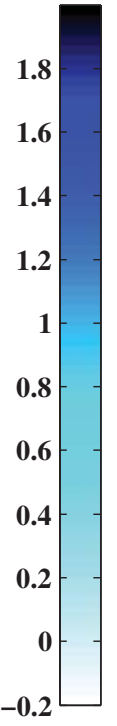

Figure 3. Comparison of slip-rate snapshots for inversions of a Haskell pulse with $V_{r}=2 \mathrm{~km} / \mathrm{s}, T_{r}=1 \mathrm{~s}$, and three different network configurations: $20 \mathrm{~km}$ network spacing (column 2), $4 \mathrm{~km}$ network spacing (column 3), and $20 \mathrm{~km}$ network spacing adjusted such that the closest stations are $4 \mathrm{~km}$ away from the fault (column 4). Because the inversion results in columns 2 and 4 are quite similar, this example confirms that the network spacing is the determining factor for the rise-time resolution, and not the distance of the closest stations to the fault.

confidently used in source inversion due to the poor knowledge about the crustal velocity structure (Ide et al., 2005; Ide, 2007), except for well-calibrated velocity models in studies of well recorded relatively small earthquakes (e.g., Wei et al., 2013). For the longer rise times of $4 \mathrm{~s}$, the pulse width as well as the peak slip rate are well constrained in the inversions from dense datasets. Coarser networks (spacing of the order tens of kilometers) broaden the pulse and decrease the peak slip rate. A commonly observed issue of loss of resolution with depth (Custódio et al., 2009; Page et al., 2009) is also evident in Figure 2.

We find that both the station spacing and the distance of the nearest stations to the fault affects the inversion. Moving the $20 \mathrm{~km}$ network so that the closest stations are at the distance of $4 \mathrm{~km}$ from the fault, we find that the inversion is similar to the $20 \mathrm{~km}$ network with the closest stations $20 \mathrm{~km}$ from the fault, and it is not as good as that with the $4 \mathrm{~km}$ network (Fig. 3). This result suggests that the network spacing is an important parameter. At the same time, it is clear that if a dense network of given aperture is placed very far from the fault, its narrow angular coverage of the focal sphere may negatively affect source inversion. We confirm this intuition by considering a case with the $4 \mathrm{~km}$ network moved so that the nearest station to the fault is $20 \mathrm{~km}$ away. The inversion results (not shown here) are indeed worse than that of $4 \mathrm{~km}$ network. This suggests that both spacing between stations and distance of the closest stations from the fault are important to achieve good resolution in source inversion. These two parameters are related, because placing the network too far from the fault would effectively result in a network of heterogeneous density (sparser near the fault).

Quantitative estimation of the goodness of the inverted rise-time values can be obtained from the slip-rate distribution. Because we do not impose non-negativity and smoothing constraints, slip rate exhibits an oscillatory behavior at the onset and cessation of slip. Hence, we use slip accumulation to estimate the rise time. Specifically, we compute the rise time as the time taken for slip on a subfault to go from $20 \%$ to $80 \%$ of its final value. The rise-time estimates obtained for each subfault are converted into one nondimensional number for the entire fault plane by taking the ratio of the median value of the rise time over the whole fault to that of the input rise time. Repeating this rise-time calculation for each input rise time and network spacing in Figure 2, a contour plot is constructed for the inverted rise time (Fig. 4). Values of 1 indicate good recovery of the rise time, with higher values indicating progressive smearing of the slip pulse. Selecting an acceptable value for the goodness of the recovered rise time (e.g., a factor of 2) partitions the parameter space into two regions, one of which (that of longer rise times and denser networks, bottom right in Fig. 4) allows for acceptable recovery of the rise time. Hence, one should be careful while interpreting inverted rise times when they are obtained based on network spacings of tens of kilometers and nonparametric source inversion methods. 


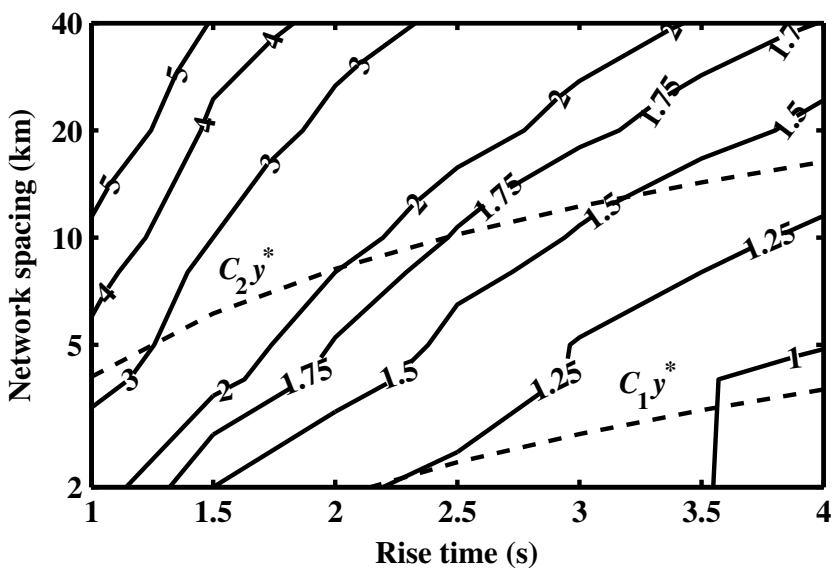

Figure 4. Contours of the ratio of the median inverted rise-time estimates over the entire fault to the input rise times, for the cases with $V_{r}=2 \mathrm{~km} / \mathrm{s}$ of Figure 2 . Once a suitable quality factor, for example, 2, is selected, the parameter space is partitioned into two areas, with the top-left portion providing unreliable estimates. The dashed lines $C_{1} y^{*}$ and $C_{2} y^{*}$ show theoretical and empirical estimates of penetration distance, in which $y^{*}$ is the characteristic lengthscale for the decay of the wavefield normal to the fault estimated in a simple model.

Effect of Rupture Velocity on the Resolution of Rise Time

Rupture velocity can affect the resolvability of the source parameters, including the rise time. In particular, supershear ruptures have particle velocities decaying slower away from the fault than subshear ruptures (Aagaard and Heaton, 2004; Bernard and Baumont, 2005; Dunham and Archuleta, 2005; Cruz-Atienza et al., 2009) owing to the presence of Mach cones (Bizzarri and Spudich, 2008; Cruz-Atienza and Olsen, 2010). For this reason, we repeat the study of the previous section for a supershear rupture speed of $V_{r}=5 \mathrm{~km} / \mathrm{s}$. The results (Fig. 5) show that the resolution of the rise time is much better for the supershear case, as expected. The rise time being resolved within a factor of 2 in all supershear cases considered.

A plane-wave analysis of steady-state pulselike rupture in $2 \mathrm{D}$ provides some rudimentary explanation for the better resolvability of supershear ruptures compared to subshear ruptures. Consider the $2 \mathrm{D}$ problem of a slip pulse propagating in steady state with rupture speed $V_{r}$. The complete wavefield is made of plane waves with apparent phase velocity along the rupture direction $(x)$ equal to $\omega / k=V_{r}$, in which $\omega$ is the circular frequency and $k$ is the wavenumber along $x$. The particle velocity associated with these waves is proportional to $e^{i(-\omega t+k x+l y)}$ in which $k^{2}+l^{2}=\omega^{2} / c^{2}$ and $c$ is a wavespeed. The wavenumber $l$ along the fault-normal direction $y$ is then given by

$$
l^{2}=\frac{\omega^{2}}{c^{2}}-k^{2}=\omega^{2}\left(\frac{1}{c^{2}}-\frac{1}{V_{r}^{2}}\right) .
$$

In the case of supershear ruptures, $l^{2}>0$ and $l$ is real for $S$ waves, leading to homogeneous $S$ waves that propagate with-

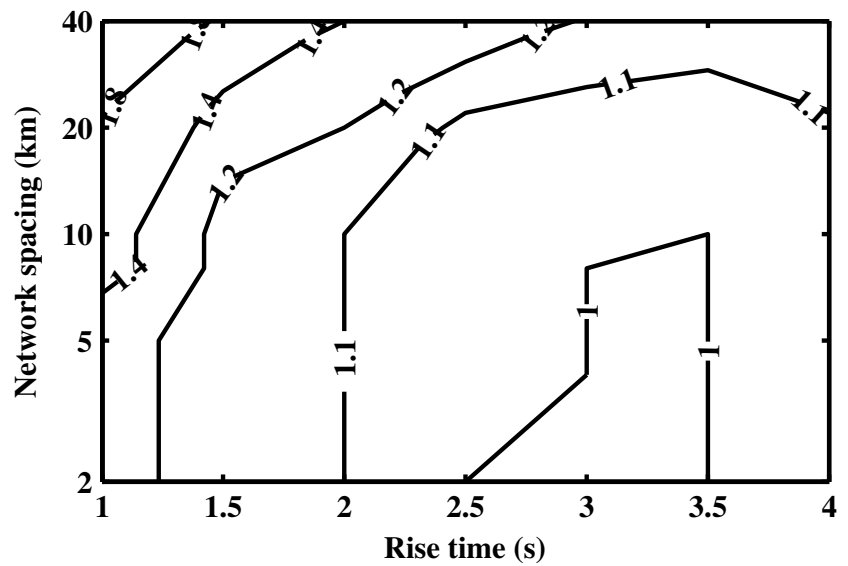

Figure 5. Contours of the ratio of the median inverted rise-time estimates over the entire fault to the input rise times, for the cases with the supershear rupture speed of $V_{r}=5 \mathrm{~km} / \mathrm{s}$. The inverted rise times are well resolved for all values of the rise time and station spacing.

out attenuation. In the case of subshear ruptures, $l$ is imaginary for both $P$ and $S$ waves, which leads to inhomogeneous waves that decay exponentially as a function of distance from the fault. Their amplitude is proportional to $e^{-|y| / y^{*}}$, in which the characteristic decay length scale is

$$
y^{*}=\frac{1}{\operatorname{Im}(l)}=\frac{1}{\omega \sqrt{\frac{1}{V_{r}^{2}}-\frac{1}{c_{s}^{2}}}} .
$$

This length scale depends on frequency. Focusing on frequencies near $1 / T_{r}$, which are necessary to temporally resolve the rise time, we define

$$
y^{*}=\frac{V_{r}}{2 \pi} \frac{T_{r}}{\sqrt{1-\left(V_{r} / c_{s}\right)^{2}}} .
$$

For subshear ruptures, we propose that the minimum station spacing required to resolve the rise time $T_{r}$ of a rupture propagating at $V_{r}$ is proportional to $y^{*}$. We define the penetration distance $C_{1} y^{*}$ over which the amplitude of the inhomogeneous wave, $e^{-\left(y / y^{*}\right)}$, decreases by $90 \%$. We find $C_{1}=2.3$. The penetration distance should be thought of as a spatial scale for the decay in the peak ground velocity (PGV) not just right next to the fault but more generally at all distances. Figure 4 shows that the curve $C_{1} y^{*}$ has the same general trend as the contours of the rise-time resolution, generally spanning the region of the good rise-time resolution values from 1 to 1.25 . This consideration implies an infinite penetration distance for the supershear case, consistent with the excellent rise-time resolution for all network spacings considered (Fig. 5).

To confirm the anticipated dependence on the rupture speed, we conduct inversions of the slip pulses with the rise time of $1 \mathrm{~s}$ propagating at a range of rupture speeds for various network spacings. A representative snapshot from each 

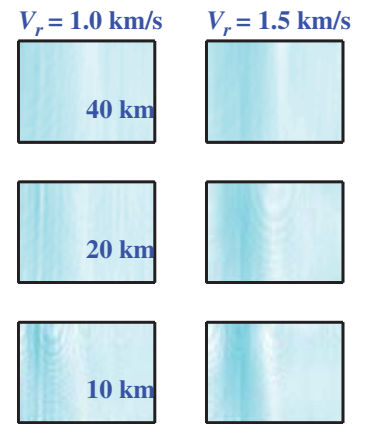

$10 \mathrm{~km}$
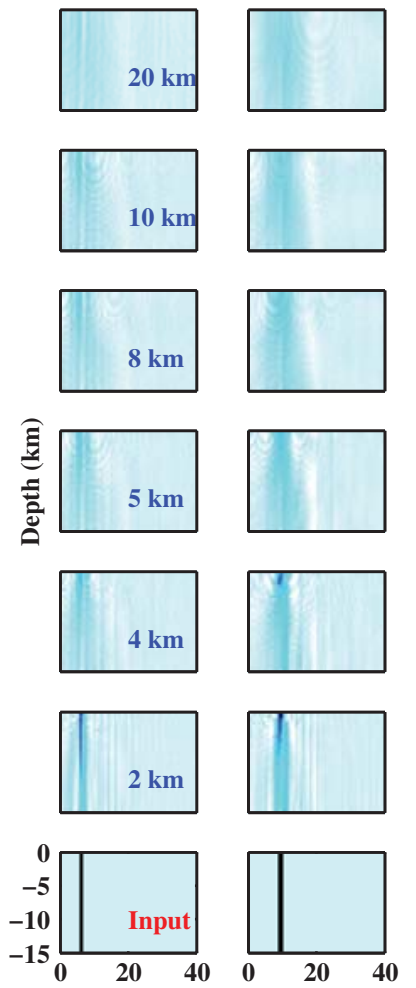

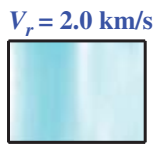

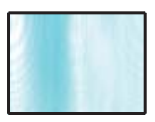
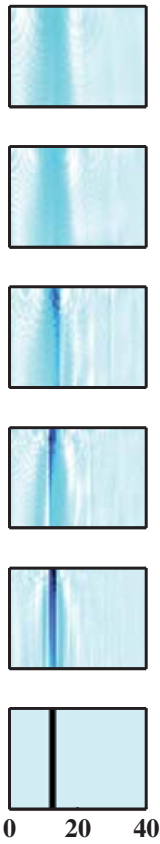
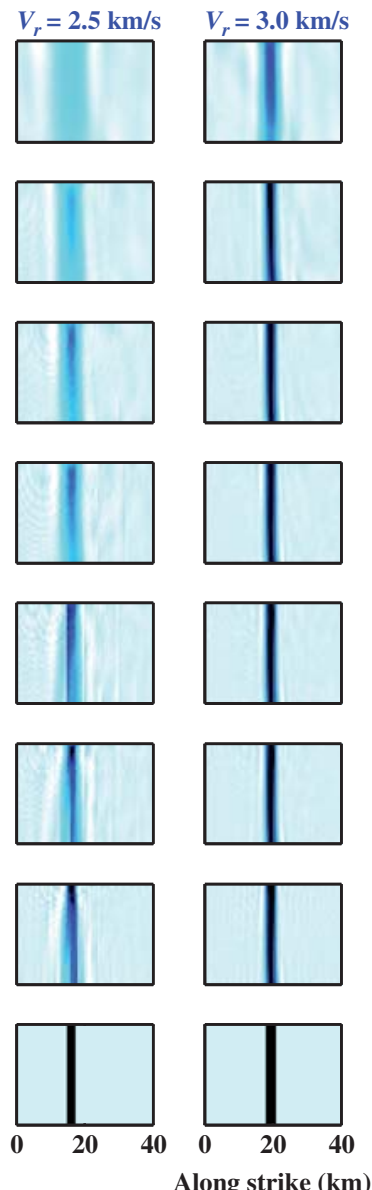
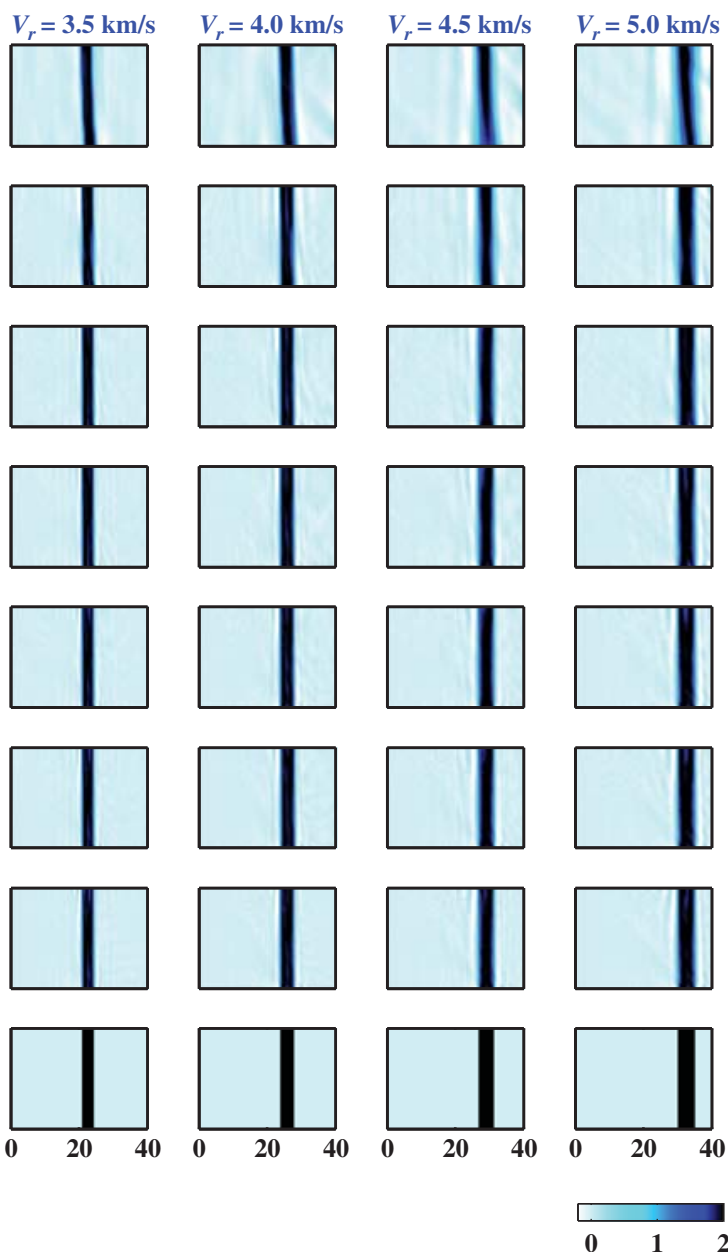

Figure 6. Representative slip-rate snapshots for the input (bottom row) and inverted source models of Haskell pulses with the rise time of $T_{r}=1 \mathrm{~s}$ and different rupture speeds. Upper rows show inversions for different network spacings, from 40 to $2 \mathrm{~km}$. Columns correspond to different rupture speeds, from 1 to $5 \mathrm{~km} / \mathrm{s}$. In the supershear regime, the rise times are well resolved by all the networks, whereas in the subshear regime, a dense enough network is required to resolve the rise time.

inversion is shown in Figure 6. Even the station spacings of a few tens of kilometers give a recovery close to that of the input for the supershear regime, both in terms of the pulse width and peak amplitude. For the subshear regime, however, there is a clear difference in the reconstructed source from the sparse datasets compared to that from the dense datasets.

A contour map of the median value of the nondimensionalized recovered rise time is presented in Figure 7. The contour map shows the dependence of the rise-time resolvability on the rupture speed and rise time. Supershear ruptures allow for resolvability of the rise time even for station spacing up to $10 \mathrm{~km}$ whereas subshear ruptures always have a resolvability factor in excess of unity even for dense networks (Fig. 7). Furthermore, rise times for rupture velocity as low as $1 \mathrm{~km} / \mathrm{s}$ are poorly resolved (off by a factor of 10) when station spacings higher than $10 \mathrm{~km}$ are used. This can be explained by considering the PGV as a function of the distance from the fault along the line passing through the middle of the fault trace (Fig. 8). PGV decays relatively slower with distance for cases with supershear rupture speeds. On the other hand, PGV for the cases with subshear speeds decays by more than an order of magnitude at about $10 \mathrm{~km}$ distance, not preserving the source information. An empirical estimate of decay in ground velocity for subshear ruptures can be obtained as the distance after which PGV decreases by a certain amount, for example, $90 \%$. This distance represented by dotted lines in Figure 8 is approximately ten times $y^{*}$. We denote this empirical estimate of the penetration distance by $C_{2} y^{*}$. The theoretical penetration distance $C_{1} y^{*}$ is shown by dashed lines in Figure 8 . There is a significant difference between the actual PGV penetration distance and the theoretical plane-wave penetration distance, as we have considered a simplified case of a 2D line fault and monochromatic plane waves to construct the crude theory. However, 3D and broadband effects seem important enough that they cannot be neglected. Nevertheless, $C_{1} y^{*}$ and $C_{2} y^{*}$ seem to give a good estimate of the network spacing that allows for rise-time resolvability factors of 1 and 2, respectively (Figs. 4 and 7). 


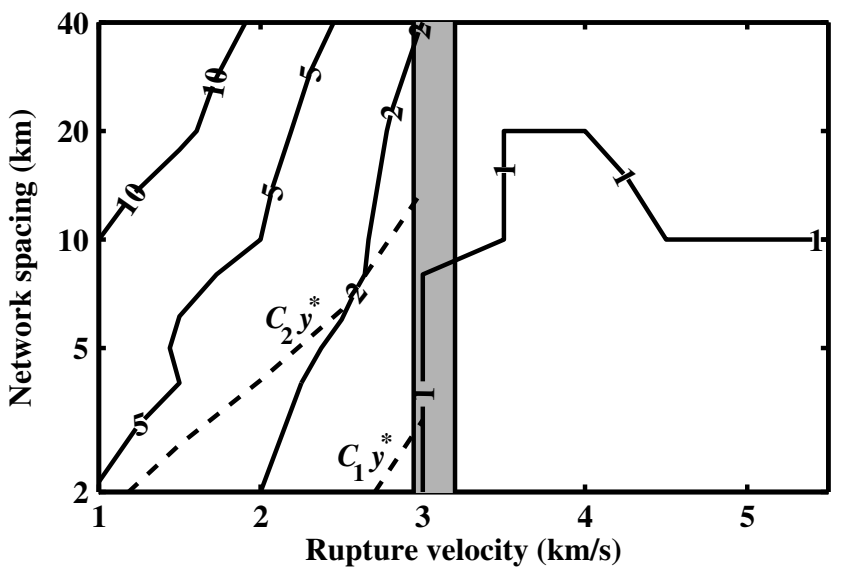

Figure 7. Contours of the ratio of the median inverted rise-time estimates over the entire fault to the input rise time of $T_{r}=1 \mathrm{~s}$ for different rupture velocities and network spacings. For supershear rupture velocities, all the networks seem to resolve the rise time well. In the cases with sub-Rayleigh rupture speeds, the resolution progressively deteriorates for lower rupture velocities.

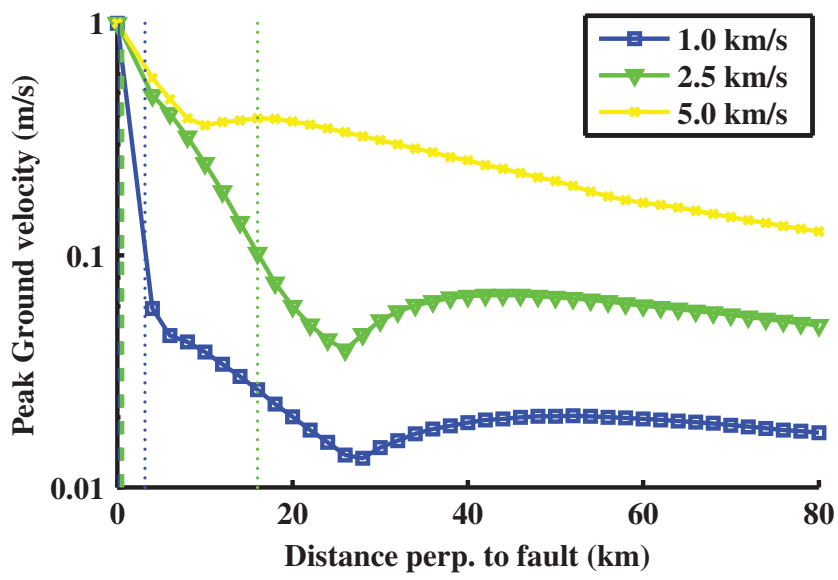

Figure 8. Peak ground velocity (PGV) as a function of distance from the fault for the $T_{r}=1 \mathrm{~s}$ Haskell pulse with different rupture velocities. The supershear rupture has slow fall off of PGV with distance compared to the subshear cases. The dashed lines represent the theoretical estimate of penetration distance $C_{1} y^{*}$ whereas dotted lines represent empirical estimate $C_{2} y^{*}$.

Having found that slip-rate recovery depends on the rupture velocity and the rise time, we now examine how slip recovery depends on these factors. Figure 9 shows the along-strike average of final slip plotted as a function of depth for the smallest and largest rise times considered $\left(T_{r}=1 \mathrm{~s}\right.$ and $\left.T_{r}=4 \mathrm{~s}\right)$, rupture speed of $2 \mathrm{~km} / \mathrm{s}$ and several network spacings. The depth profiles of recovered slip are very similar for both end-member rise times in the subshear regime, in which slip rate shows substantial variations in recovery. Variability in the shape of the slip profile with the network spacing is minimal. The general trend is underprediction at deeper portions of the fault and minor overprediction at intermediate depths. The recovery of slip may be

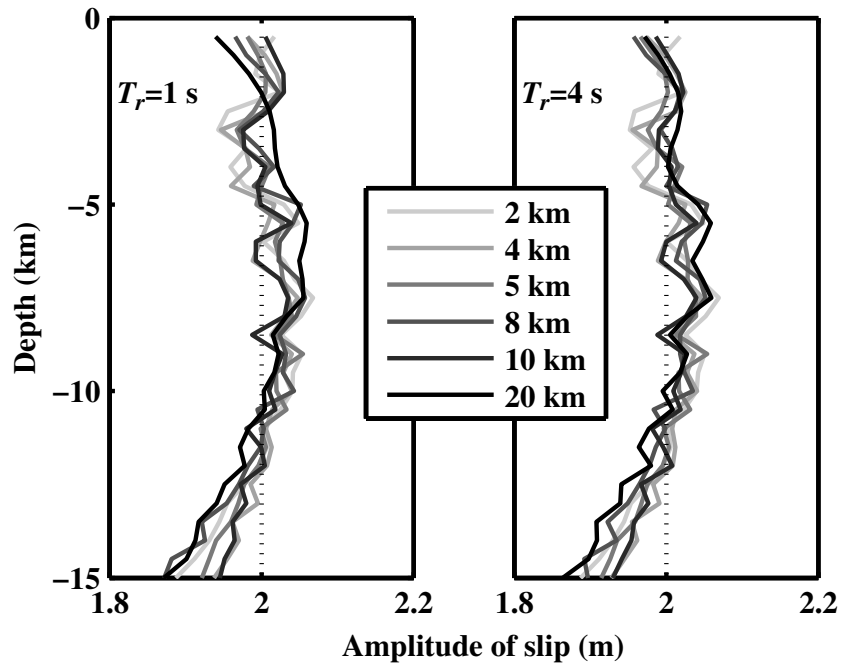

Figure 9. Depth profiles of final slip averaged along strike recovered in source inversions of scenarios with rupture speed of $2 \mathrm{~km} / \mathrm{s}$, uniform final slip of $2 \mathrm{~m}$ and rise times of $T_{r}=1 \mathrm{~s}$ (left) and $T_{r}=4 \mathrm{~s}$ (right). Each curve corresponds to a separate inversion with different network spacing (see legend). Depth-averaged slip recovery is independent of the rise time or network spacing.

poorer in practice if data needs to be high-pass filtered to remove long-period instrumental artifacts.

Because slip is well resolved by our inversions, the errors in rise time are directly mapped into errors in average slip rates, which would affect the far-field displacement. For example, if the rise time is overestimated by a factor of 4 , then the slip rates are underestimated by a factor of 4 on average.

\section{Rise-Time Resolvability for Variable Rupture Speed}

The scenarios considered so far have a constant rupture speed over the entire fault plane. Variations in rupture speed will change the radiation character and hence can affect the resolution of the inversion. Let us consider a scenario with a variable rupture speed, in which rupture speed switches between 2 and $3 \mathrm{~km} / \mathrm{s}$ every $10 \mathrm{~km}$ along strike. The rise time is kept constant at $1 \mathrm{~s}$. We use data from a $5 \mathrm{~km}$ spaced network in this inversion. We choose these particular combinations of rise time, rupture speeds, and network spacing because in the corresponding inversions with a constant rupture speed the $3 \mathrm{~km} / \mathrm{s}$ case has clearly a better resolution of rise time compared to that of the $2 \mathrm{~km} / \mathrm{s}$ case. Figure 10 shows the comparison of this inversion with the constant rupture speed inversions at mid-depth along the strike. For Haskell pulses, rupture should be seen within a band of $T_{r}$ seconds having a slope of $V_{r}$. For the variable rupture speed case, the portions during which the rupture speed is slower, at $2 \mathrm{~km} / \mathrm{s}$, have poorer resolvability, similar to the inversion of the case with the $2 \mathrm{~km} / \mathrm{s}$ constant rupture speed. The portions with the faster rupture speed of $3 \mathrm{~km} / \mathrm{s}$ have better resolution, qualitatively comparable to that of the inversion of the case with the $3 \mathrm{~km} / \mathrm{s}$ uniform rupture speed. Hence, based on this 

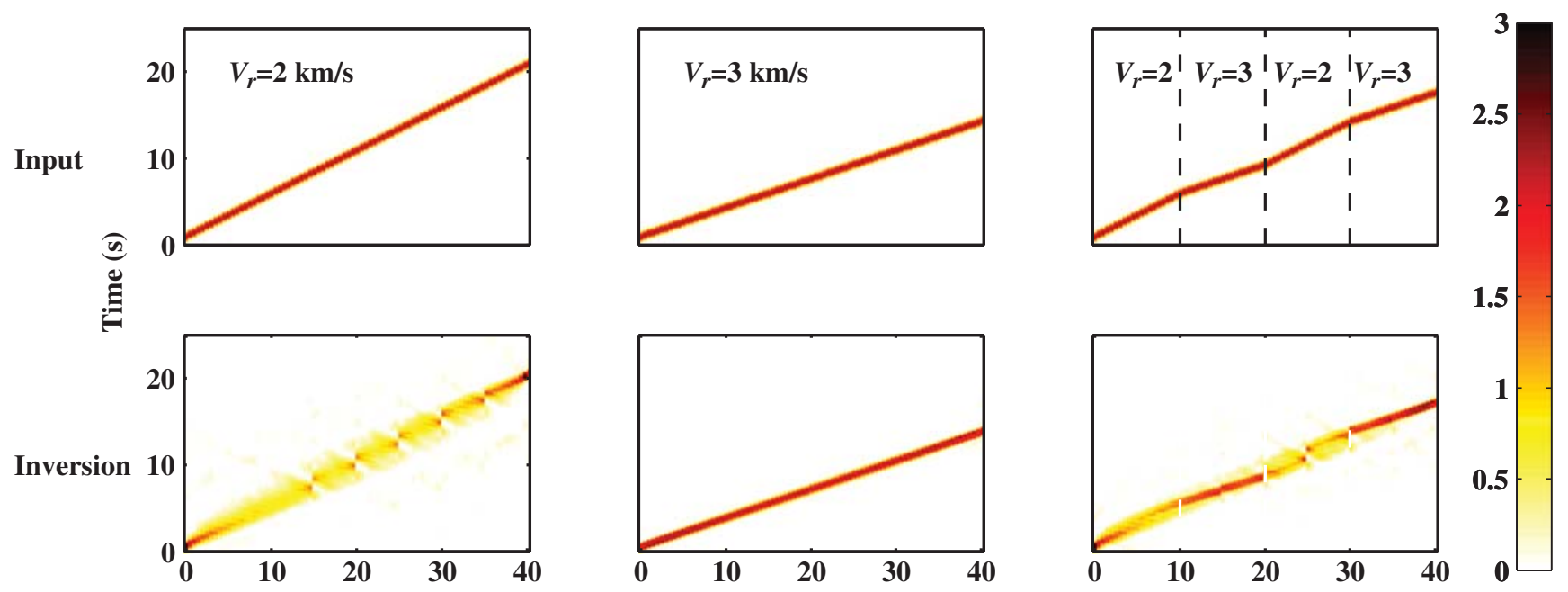

Figure 10. Space-time plot of the slip rate at the mid-depth of the fault, to test inversion of a scenario with variable rupture velocity. The scenario with $2 \mathrm{~km} / \mathrm{s}$ rupture velocity for $0<x \leq 10$ and $20<x \leq 30 \mathrm{~km}$ and $3 \mathrm{~km} / \mathrm{s}$ rupture velocity for $10<x \leq 20$ and $30<x \leq 40 \mathrm{~km}$ gives an inversion comparable to the inversion with the overall rupture speed of $2 \mathrm{~km} / \mathrm{s}$ in the regions where the rupture speed is $2 \mathrm{~km} / \mathrm{s}$ and comparable to the inversion with the overall rupture speed of $3 \mathrm{~km} / \mathrm{s}$ in the regions where the rupture speed is $3 \mathrm{~km} / \mathrm{s}$.

example, the quality of the resolution for cases with variable rupture speed can be determined from corresponding inversions with constant rupture speeds, a conclusion that requires further study.

\section{Trade-Off between Noise and Network Spacing}

A higher spatial density of surface measurements may come at the expense of noise, and hence it is important to consider the trade-off between network spacing and data noise. For example, future earthquake observation systems based on satellite imaging may be able to provide recordings as dense as few hundred meters (Michel et al., 2013). However, the disturbances in atmosphere and other factors contribute to an uncorrelated additive noise with standard deviation of $\sim 1 \mathrm{~cm} / \mathrm{s}$.

Let us consider the following two cases, one with $3 \mathrm{~km} / \mathrm{s}$ rupture velocity, which gives a good estimate of rise time for both sparse $(20 \mathrm{~km})$ as well as dense $(2 \mathrm{~km})$ networks, and the other with $2 \mathrm{~km} / \mathrm{s}$ rupture velocity, which gives a poor estimate of rise time for sparse networks. For each of the cases, we add Gaussian uncorrelated noise of $1 \mathrm{~cm} / \mathrm{s}$ standard deviation to the data from the dense network, while still keeping the sparse network data noiseless. The maximum amplitude of velocities in the close vicinity of the fault is one-half of the slip rate imposed, which is $1 \mathrm{~m} / \mathrm{s}$ in both cases. We see (Figs. 11 and 12) that the slip rate from inversions of the dense network data with $1 \mathrm{~cm} / \mathrm{s}$ noise is quite similar to that of inversions based on the dense network data without any noise, a positive finding for space-based observation systems like that proposed by Michel et al. (2013). The noise added here is spatially uniform, but errors in the bulk structure lead to multiplicative noise (i.e., the amplitude of which is some percentage of the PGV at each station) that can substantially degrade the quality of the dense- network inversion, as discussed in Somala et al. (unpublished manuscript, 2014).

\section{Conclusions}

Following the developments of Somala et al. (unpublished manuscript, 2014), we present an adjoint linear method for kinematic source inversion with unrestricted multiple time windows based on precomputed GFs for a homogenous halfspace. (The work of Somala et al., unpublished manuscript, 2014, does not use precomputed GFs.) The only constraint in this nonparametric inversion method is the assumed fault geometry. There are no assumptions or constraints on the rupture speed, rise time, or shape of the source time function. We then use the method to assess, through synthetic inversion tests, the effect of the average network spacing and rupture velocity on the rise-time resolution. The range of the station spacing considered is motivated by the spacing of a few tens of kilometers for the best currently available seismic networks as well as by the potentially much denser networks of the future. To the best of our knowledge, seismic source inversion has never been attempted before for datasets as large as for the densest network used here. We focus on fundamental aspects of the problem by considering a simplistic earthquake scenario, a Haskell pulse with uniform rupture speed, slip, and rise time on a vertical strike-slip fault.

We find that the rise-time resolution strongly depends on the rupture speed (see Fig. 6). For supershear rupture speeds, the resolution of the rise time is excellent in all cases, up to the temporal resolution limit imposed by the frequency band of the filtered data. Rise times longer than $1 \mathrm{~s}$ are resolved within a factor of two by networks with spacing from 2 to $40 \mathrm{~km}$ with data filtered below $1 \mathrm{~Hz}$. For subshear rupture speeds, the rise-time resolution strongly depends on the 


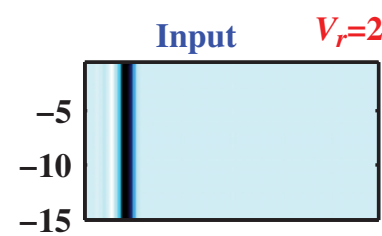

$20 \mathrm{~km}$, noiseless
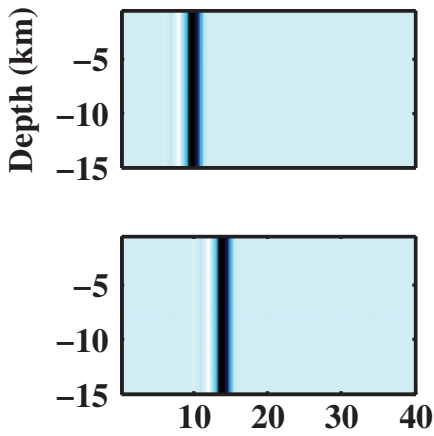
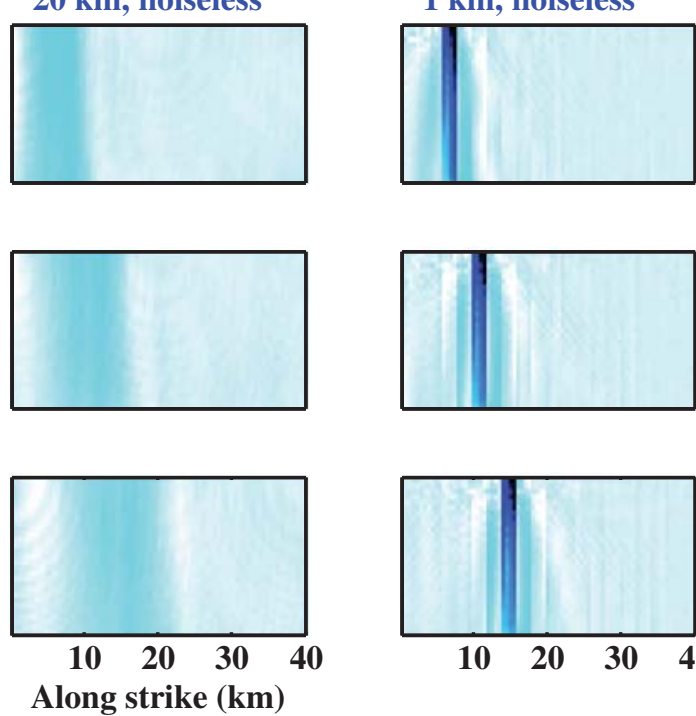

$1 \mathrm{~km}$, noiseless

$1 \mathrm{~km}, 1 \mathrm{~cm} / \mathrm{s}$ noise

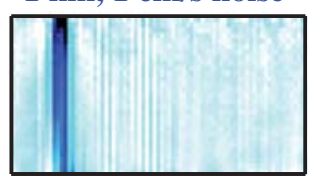

2
1.5

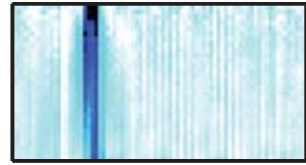

1

0.5
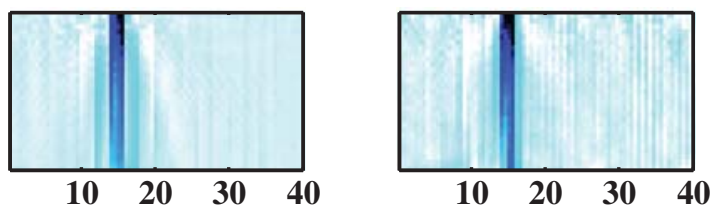

0

Figure 11. Slip-rate snapshots from inversion with a noise of $1 \mathrm{~cm} / \mathrm{s}$ added to the dense network data and its comparison to its noiseless counterpart and a sparse network inversion for $V_{r}=2 \mathrm{~km} / \mathrm{s}$. The recovery of the dense network with $1 \mathrm{~cm} / \mathrm{s}$ noise added to its data is qualitatively similar to the dense network recovery without noise.
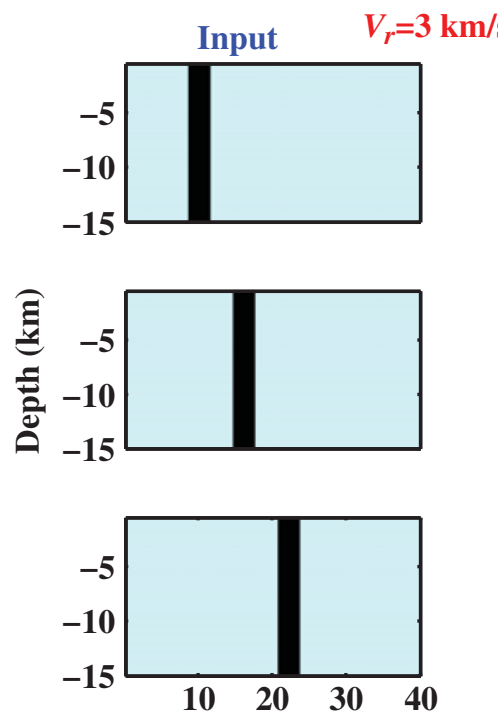

$1 \mathrm{~km}$, noiseless
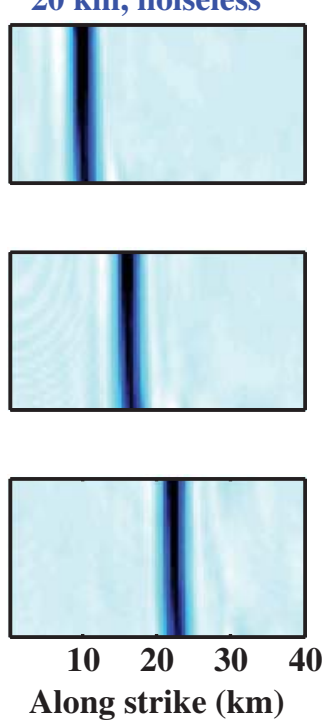

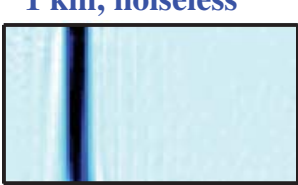

$1 \mathrm{~km}, 1 \mathrm{~cm} / \mathrm{s}$ noise
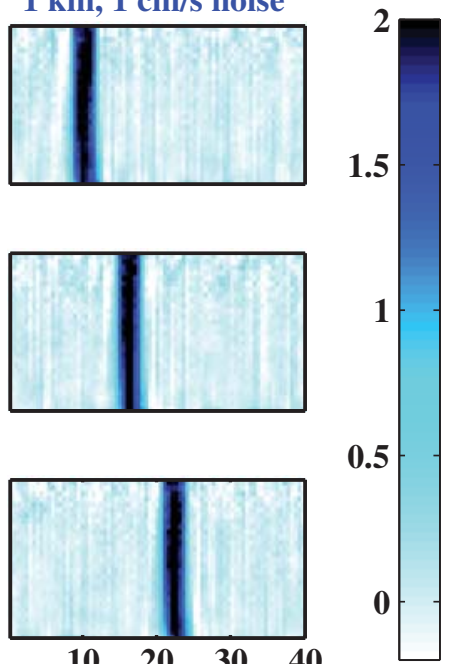

Figure 12. Same as Figure 11 for $V_{r}=3 \mathrm{~km} / \mathrm{s}$.

value of the rise time and the network spacing (See Fig. 2). The smaller the rupture speed and the shorter the rise time, the denser the network needs to be. For denser arrays (i.e., spacing smaller than about $10 \mathrm{~km}$ ) and slip pulses longer than about $2 \mathrm{~s}$, the rise time is resolved within a factor of two for ruptures with subshear speeds. Both the network spacing and the distance of the closest stations to the fault are important parameters.

The difference between the supershear and subshear cases can be explained by the difference in the decay of the PGVs away from the fault. Theoretically, a penetration dis- tance of shear waves away from the fault can be defined based on a simplified model of a line fault in $2 \mathrm{D}$. The penetration distance is infinite for the supershear cases in the simple 2D example unlike the subshear cases in which it is finite. In the $3 \mathrm{D}$ cases considered numerically, there is a decay of the PGVs even for the supershear cases, consistent with prior studies (e.g., Dunham and Archuleta, 2005; CruzAtienza and Olsen, 2010), but the decay is much slower than for the subshear case. Overall, our numerical simulations show that the theoretical estimate of the penetration distance derived in this study correctly captures the qualitative trends 
but does not provide a precise quantitative estimate. Variable supershear rupture speed arising on heterogeneous faults decreases the coherence of the Mach front and hence reduces the PGV (Bizzarri et al., 2010), potentially reducing the risetime resolution. The effects of network spacing on the resolution of rise time were here linked to the properties of the wavefield and not to anything method related. We hence expect them to hold, at least qualitatively, for parametric source inversion methods.

Our conclusions on rise-time resolvability are independent of the pulse shape used, as verified using both Haskell and Yoffe slip-rate functions. In the supershear cases, the asymmetry of the regularized Yoffe pulse can be resolved with all network spacings considered (Fig. B2). In the subshear case, the inversions for the Yoffe pulses do not show a clear asymmetry. Interestingly, contrary to the inversions of slip rate, profiles of the inverted slip with depth are well resolved and quite similar for all rise times and network spacings considered, even for the subshear cases.

New observation systems with spatially dense measurements may come at the expense of an increased noise, and we have considered the effect of a uniform Gaussian additive uncorrelated noise level of $1 \mathrm{~cm} / \mathrm{s}$ characteristic of spacebased observations (Michel et al., 2013). We find that risetime resolution for dense networks with such a noise is as good as for noiseless dense networks. There are other sources of noise. In particular, this study assumes that the velocity model is known but, in real cases, there is uncertainty in the velocity model. The uncertainty can be represented by von Karman distribution with near zero Hurst exponent (Hartzell et al., 2010; Imperatori and Mai, 2012). Our prior study (Somala et al., unpublished manuscript, 2014) indicates that, as long as the standard deviation of the von Karman distribution of the uncertainty is less than $1 \%$ or its correlation length is less than $0.5 \mathrm{~km}$, the results of this study would still hold. This is a much more stringent requirement than the currently estimated uncertainty parameters, which are 5\% standard deviation and $5 \mathrm{~km}$ (Hartzell et al., 2010). However, better knowledge of the bulk structure may be obtained in the future with denser seismic observation systems.

\section{Data and Resources}

No data were used in this paper. All plots were made using MATLAB (http://www.mathworks.co.uk/products/ matlab/; last accessed October 2014). Simulations were conducted in Caltech's CITerra/Fram cluster and Green's functions were computed with "Computer programs in seismology" (Herrmann, 2013), obtained from the Saint Louis University Earthquake Center at http://www.eas.slu.edu/eqc/ eqccps.html (last accessed August 2014).

\section{Acknowledgments}

This study was supported by the Keck Institute for Space Studies at Caltech, which is funded by the W. M. Keck Foundation and by National Science Foundation Grant Number EAR-1151926. We thank Zacharie Du- putel for help with the Green's functions database generation. We also thank František Gallovič and Víctor Manuel Cruz-Atienza for thoughtful reviews that helped us improve the manuscript.

\section{References}

Aagaard, B. T., and T. H. Heaton (2004). Near-source ground motions from simulations of sustained intersonic and supersonic fault ruptures, Bull. Seismol. Soc. Am. 94, no. 6, 2064-2078.

Aki, K., and P. G. Richards (2002). Quantitative Seismology, University Science Books, Sausalito, California.

Archuleta, R. J. (1984). A faulting model for the 1979 imperial valley earthquake, J. Geophys. Res. 89, no. B6, 4559-4585, doi: 10.1029/ JB089iB06p04559.

Beresnev, I. A. (2003). Uncertainties in finite-fault slip inversions: To what extent to believe? (A critical review), Bull. Seismol. Soc. Am. 93, no. 6, 2445-2458, doi: 10.1785/0120020225.

Berman, D. H. (1997). Computing effective reflection coefficients in layered media, J. Acoust. Soc. Am. 101, no. 2, 741-748, doi: 10.1121/1.418037.

Bernard, P., and D. Baumont (2005). Shear Mach wave characterization for kinematic fault rupture models with constant supershear rupture velocity, Geophys. J. Int. 162, no. 2, 431-447.

Bizzarri, A., and P. Spudich (2008). Effects of supershear rupture speed on the high-frequency content of $\mathrm{S}$ waves investigated using spontaneous dynamic rupture models and isochrone theory, J. Geophys. Res. 113, no. B5, doi: 10.1029/2007JB005146.

Bizzarri, A., E. M. Dunham, and P. Spudich (2010). Coherence of Mach fronts during heterogeneous supershear earthquake rupture propagation: Simulations and comparison with observations, J. Geophys. Res. 115, no. B8, doi: 10.1029/2009JB006819.

Clayton, R. W., T. Heaton, M. Chandy, A. Krause, M. Kohler, J. Bunn, R. Guy, M. Olson, M. Faulkner, M. Cheng, L. Strand, R. Chandy, D. Obenshain, A. Liu, and M. Aivazis (2012). Community seismic network, Ann. Geophys. 54, no. 6, doi: 10.4401/ag-5269.

Cruz-Atienza, V. M., and K. B. Olsen (2010). Supershear mach-waves expose the fault breakdown slip, Tectonophysics 493, nos. 3/4, 285-296, doi: 10.1016/j.tecto.2010.05.012.

Cruz-Atienza, V. M., K. B. Olsen, and L. A. Dalguer (2009). Estimation of the breakdown slip from strong-motion seismograms: Insights from numerical experiments, Bull. Seismol. Soc. Am. 99, no. 6, 3454-3469, doi: 10.1785/0120080330.

Custódio, S., M. T. Page, and R. J. Archuleta (2009). Constraining earthquake source inversions with GPS data: 2. A two-step approach to combine seismic and geodetic data sets, J. Geophys. Res. 114, no. B1, doi: 10.1029/2008JB005746.

Das, S., and B. Kostrov (1990). Inversion for seismic slip rate history and distribution with stabilizing constraints: Application to the 1986 andreanof islands earthquakes, J.Geophys. Res. 95, 6899-6913, doi: 10.1029/JB095iB05p06899.

Dunham, E. M., and R. J. Archuleta (2005). Near-source ground motion from steady state dynamic rupture pulses, Geophys. Res. Lett. 32, no. 3, doi: 10.1029/2004GL021793.

Fletcher, R., and C. M. Reeves (1964). Function minimization by conjugate gradients, Computer Journal 7, no. 2, 149-154.

Fuchs, K., and G. Müller (1971). Computation of synthetic seismograms with the reflectivity method and comparison with observations, Geophys. J. Roy. Astron. Soc. 23, no. 4, 417-433, doi: 10.1111/j.1365246X.1971.tb01834.x.

Gabriel, A.-A., J.-P. Ampuero, L. A. Dalguer, and P. M. Mai (2012). The transition of dynamic rupture styles in elastic media under velocityweakening friction, J. Geophys. Res. 117, no. B9, doi: 10.1029/ 2012JB009468.

Gallovič, F., and J. Zahradník (2011). Toward understanding slip inversion uncertainty and artifacts: 2 . Singular value analysis, J. Geophys. Res. 116, no. B2, doi: 10.1029/2010JB007814. 
Gallovič, F., J. Zahradník, D. Křížová, V. Plicka, E. Sokos, A. Serpetsidaki, and G.-A. Tselentis (2009). From earthquake centroid to spatialtemporal rupture evolution: $M_{\mathrm{w}} 6.3$ Movri Mountain earthquake, June 8, 2008, Greece, Geophys. Res. Lett. 36, no. 21, doi: 10.1029/ 2009GL040283.

Graves, R. W., and D. J. Wald (2001). Resolution analysis of finite fault source inversion using one- and three-dimensional Green's functions: 1. Strong motions, J. Geophys. Res. 106, no. B5, 8745-8766, doi: 10.1029/2000JB900436.

Hartzell, S., and T. H. Heaton (1983). Inversion of strong ground motion and teleseismic waveform data for the fault rupture history of the 1979 Imperial Valley, California, earthquake, Bull. Seismol. Soc. Am. 73, no. 6A, 1553-1583.

Hartzell, S., and C. Langer (1993). Importance of model parameterization in finite fault inversions: Application to the $1974 M_{\mathrm{w}} 8.0$ Peru earthquake, J. Geophys. Res. 98, no. B12, 22,123-22,134, doi: 10.1029/ 93JB02453.

Hartzell, S., S. Harmsen, and A. Frankel (2010). Effects of 3D random correlated velocity perturbations on predicted ground motions, Bull. Seismol. Soc. Am. 100, no. 4, 1415-1426, doi: 10.1785/0120090060.

Haskell, N. A. (1969). Elastic displacements in the near-field of a propagating fault, Bull. Seismol. Soc. Am. 59, no. 2, 865-908.

Heaton, T. H. (1990). Evidence for and implications of self-healing pulses of slip in earthquake rupture, Phys. Earth Planet. In. 64, no. 1, 1-20, doi: 10.1016/0031-9201(90)90002-F.

Herrmann, R. B. (2013). Computer programs in seismology: An evolving tool for instruction and research, Seismol. Res. Lett. 84, no. 6, 1081-1088, doi: 10.1785/0220110096.

Hestenes, M., and E. Stiefel (1952). Methods of conjugate gradients for solving linear systems, J. Res. Natl Bur. Stand. 49, no. 6, 409-436.

Ide, S. (2007). Treatise on Geophysics, Earthquake Seismology, First Edition, Vol. 4, Elsevier Science, Amsterdam, The Netherlands.

Ide, S., G. C. Beroza, and J. J. McGuire (2005). Imaging earthquake source complexity, in Seismic Earth: Array Analysis of Broadband Seismograms, A. Levander and G. Nolet (Editors), Geophysical Monograph Series, Vol. 157, 117-135.

Imperatori, W., and P. M. Mai (2012). Sensitivity of broad-band groundmotion simulations to earthquake source and Earth structure variations: An application to the Messina Straits (Italy), Geophys. J. Int. 188, no. 3, 1103-1116, doi: 10.1111/j.1365-246X.2011.05296.x.

Ji, C., D. J. Wald, and D. V. Helmberger (2002). Source description of the 1999 Hector Mine, California, earthquake, Part I: Wavelet domain inversion theory and resolution analysis, Bull. Seismol. Soc. Am. 92, no. 4, 1192-1207, doi: 10.1785/0120000916.

Konca, A. O., Y. Kaneko, N. Lapusta, and J.-P. Avouac (2013). Kinematic inversion of physically plausable earthquake source models obtained from dynamic rupture simulations, Bull. Seismol. Soc. Am. 103, no. 5, 2621-2644.

Lawson, C. L., and R. J. Hanson (1995). 23. Linear least squares with linear inequality constraints, in Solving Least Squares Problems, R. E. O’Malley Jr. (Editor), Society for Industrial and Applied Mathematics, $158-173$.

Liu, P., and R. J. Archuleta (2004). A new nonlinear finite fault inversion with three-dimensional Green's functions: Application to the 1989 Loma Prieta, California, earthquake, J. Geophys. Res. 109, no. B2, doi: 10.1029/2003JB002625

Menke, W. (1989). Geophysical Data Analysis: Discrete Inverse Theory, Academic Press, San Diego, California.

Michel, R., J. Ampuero, J. Avouac, N. Lapusta, S. Leprince, D. Redding, and S. N. Somala (2013). A geostationary optical seismometer, proof of concept, IEEE Trans. Geosci. Remote Sens. 51, no. 1, 695-703, doi: 10.1109/TGRS.2012.2201487.

Miyatake, T., M. Iida, and K. Shimazaki (1986). The effect of strong-motion array configuration on source inversion, Bull. Seismol. Soc. Am. 76, no. 5, 1173-1185.

Olson, A. H., and J. G. Anderson (1988). Implications of frequency-domain inversion of earthquake ground motions for resolving the space-time dependence of slip on an extended fault, Geophys. J. 94, no. 3, 443-455, doi: 10.1111/j.1365-246X.1988.tb02267.x.

Olson, A. H., and R. J. Apsel (1982). Finite faults and inverse theory with applications to the 1979 Imperial Valley earthquake, Bull. Seismol. Soc. Am. 72, no. 6A, 1969-2001.

Page, M. T., S. Custódio, R. J. Archuleta, and J. M. Carlson (2009). Constraining earthquake source inversions with GPS data: 1. Resolutionbased removal of artifacts, J. Geophys. Res. 114, no. B1, doi: 10.1029/ 2007JB005449.

Polak, E., and G. Ribière (1969). Note sur la convergence de directions conjugées, Rev. française Informat, Recherche Opertionelle, 3e année 16, 35-43 (in French).

Sambridge, M., and G. Drijkoningen (1992). Genetic algorithms in seismic waveform inversion, Geophys. J. Int. 109, no. 2, 323-342.

Saraò, A., S. Das, and P. Suhadolc (1998). Effect of non-uniform station coverage on the inversion for earthquake rupture history for a Haskell-type source model, J. Seismol. 2, no. 1, 1-25, doi: 10.1023/ A:1009795916726.

Sekiguchi, H., K. Irikura, and T. Iwata (2000). Fault geometry at the rupture termination of the 1995 Hyogo-ken Nanbu earthquake, Bull. Seismol. Soc. Am. 90, no. 1, 117-133.

Sen, M. K., and P. L. Stoffa (1991). Nonlinear one-dimensional seismic waveform inversion using simulated annealing, Geophysics 56, no. 10, 1624-1638, doi: 10.1190/1.1442973.

Shao, G., and C. Ji (2012). What the exercise of the SPICE source inversion validation BlindTest 1 did not tell you, Geophys. J. Int. 189, no. 1, 569-590, doi: 10.1111/j.1365-246X.2012.05359.x.

Tarantola, A. (2005). Inverse problem theory and methods for model parameter estimation, SIAM, ISBN: 0-89871-572-5.

Tinti, E., E. Fukuyama, A. Piatanesi, and M. Cocco (2005). A kinematic source-time function compatible with earthquake dynamics, Bull. Seismol. Soc. Am. 95, no. 4, 1211-1223, doi: 10.1785/0120040177.

Wei, S., D. Helmberger, S. Owen, R. W. Graves, K. W. Hudnut, and E. J. Fielding (2013). Complementary slip distributions of the largest earthquakes in the 2012 Brawley swarm, Imperial Valley, California, Geophys. Res. Lett. 40, no. 5, 847-852, doi: 10.1002/grl.50259.

Yoffe, E. H. (1951). The moving Griffith crack, Phil. Mag. 42, no. 330, 739-750.

\section{Appendix A}

\section{Convergence Criteria in Data and Model Spaces}

Here, we present how the error metrics vary as a function of space, time, or iteration number. We use inversions for the Haskell pulse with $T_{r}=1 \mathrm{~s}$ and $V_{r}=2 \mathrm{~km} / \mathrm{s}$ to illustrate the error trends, which are similar to those of other cases.

The misfit function defined by equation (2) is the same as variance, and its ratio to the variance of the data gives the normalized variance shown in Figure A1. We emphasize that here and in the rest of this section, the equations for the root mean square (rms) error are not normalized whereas the figures show normalized quantities. The normalized variance of 0.01 or, equivalently, the variance reduction of $99 \%$ is achieved in this example with less than 50 iterations; however, it continues to improve with further iterations. If we compare the inverted models obtained at the 50th and the 500th iterations, they are quite different; the typical snapshots after 500 iterations are shown in Figure 2 of the main text whereas the corresponding snapshots after 50 iterations are given in Figure A2. Clearly, the depth resolution is much improved after 500 iterations. A criterion for the required 


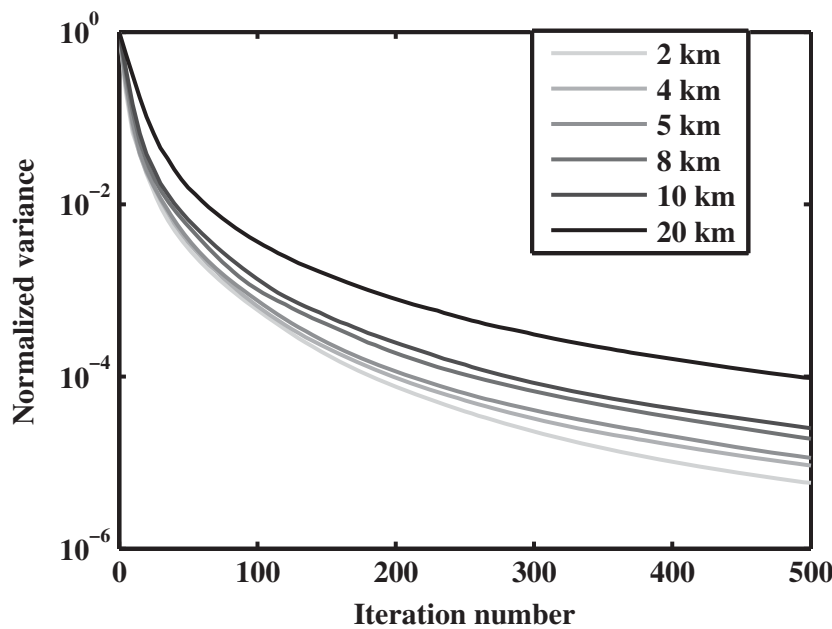

Figure A1. Normalized variance of data as a function of iteration number. Denser networks produce more rapid reduction in the normalized variance than sparser networks. number of iterations needs to be established, in which models at different iterations are compared and the iterations are stopped when the corresponding models are sufficiently similar at the relevant temporal and spatial scales. Such a criterion is beyond the scope of this study. However, the convergence has been reached in this study, because the models at 250 iterations (Fig. A3) are quite similar to the ones at 500 iterations (Fig. 2).

The rms error of the model at each iteration is defined as

$$
\Psi^{2}(\mathbf{m})=\int_{0}^{T} \sum_{s=1}^{N_{\text {sub-fault }}}\left\|\mathbf{m}\left(\mathbf{x}_{s}, t\right)-\mathbf{m}^{\mathbf{0}}\left(\mathbf{x}_{s}, t\right)\right\|^{2} d t
$$

in which $\mathbf{m}$ is the model, $\mathbf{m}^{\mathbf{0}}$ is input source, $T$ is the total duration of the observation, and $s$ is the number of subfaults. The model rms error as a function of the iteration number is shown in Figure A4, normalized by the difference between the maximum and minimum values. Figure A4 demonstrates that the normalized rms error substantially decreases in the initial 10 or so iterations for all network spacings, with
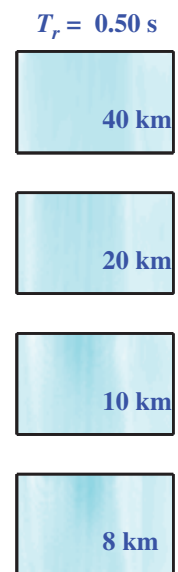

气્
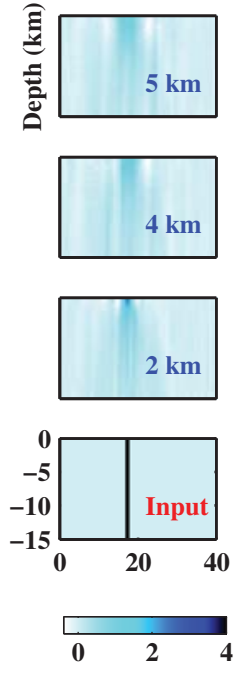
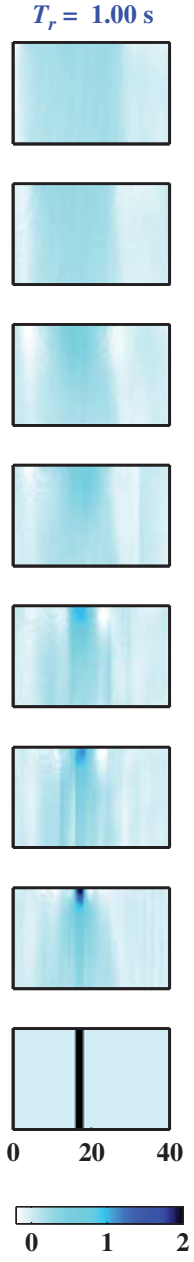
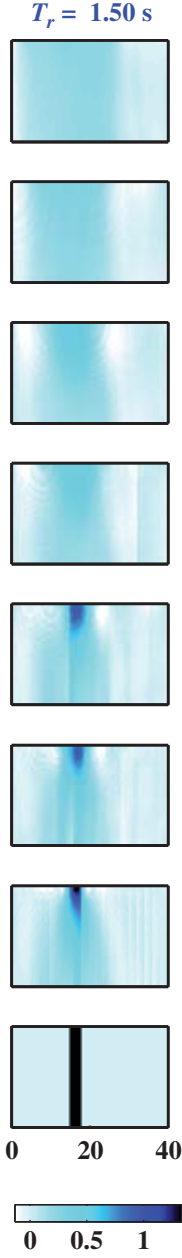
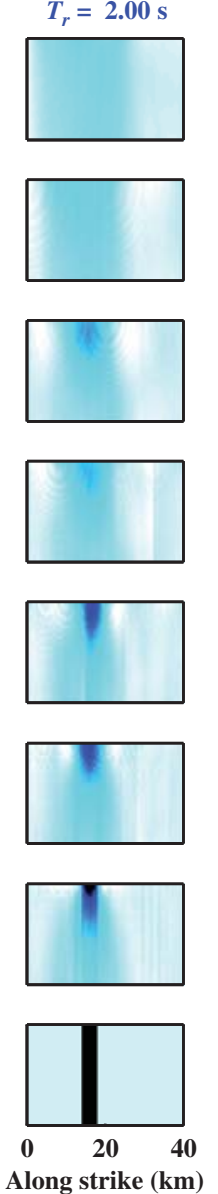

Along strike (km)

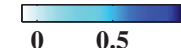

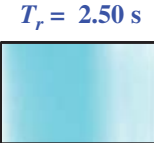
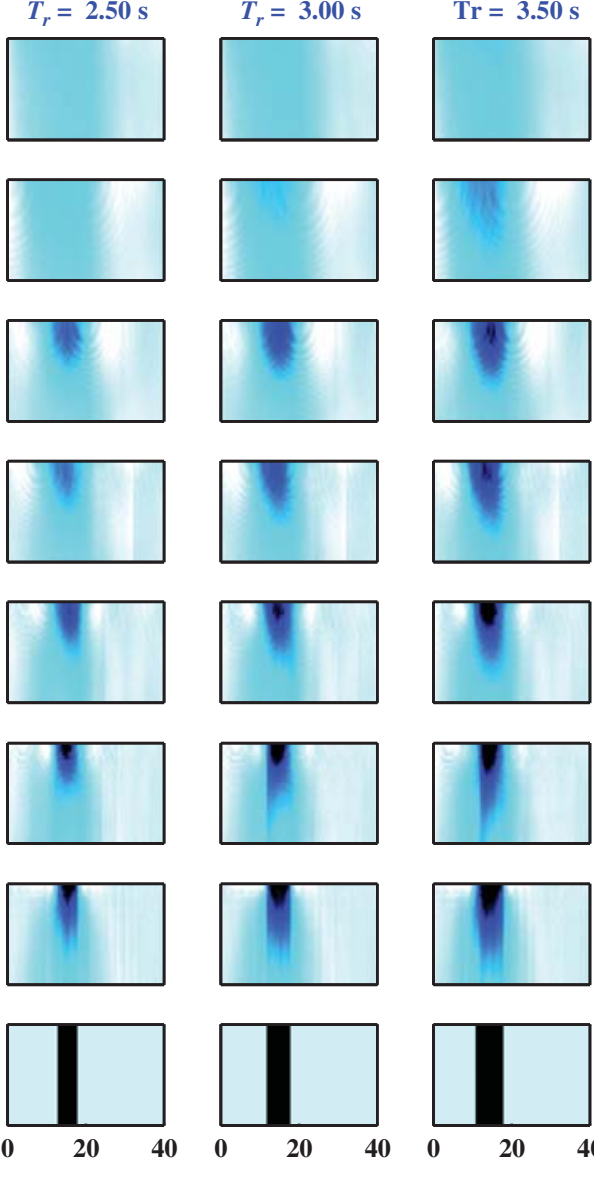

00.20 .40 .6
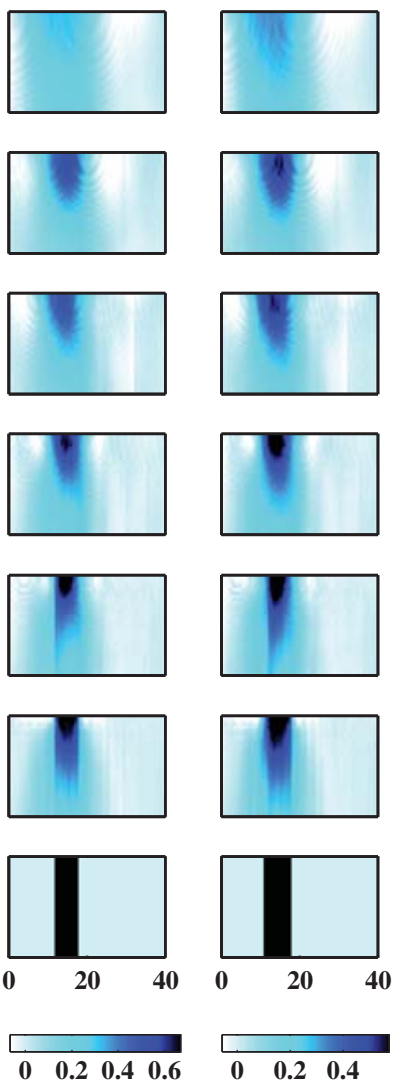
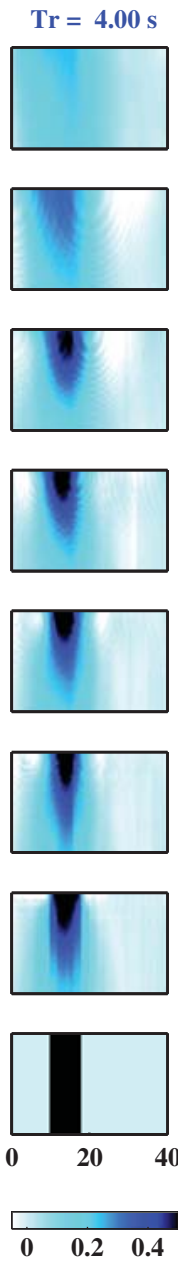

Figure A2. The same snapshots as in Figure 2 at 50 iterations. Figure 2 gives the snapshots after 500 iterations. 

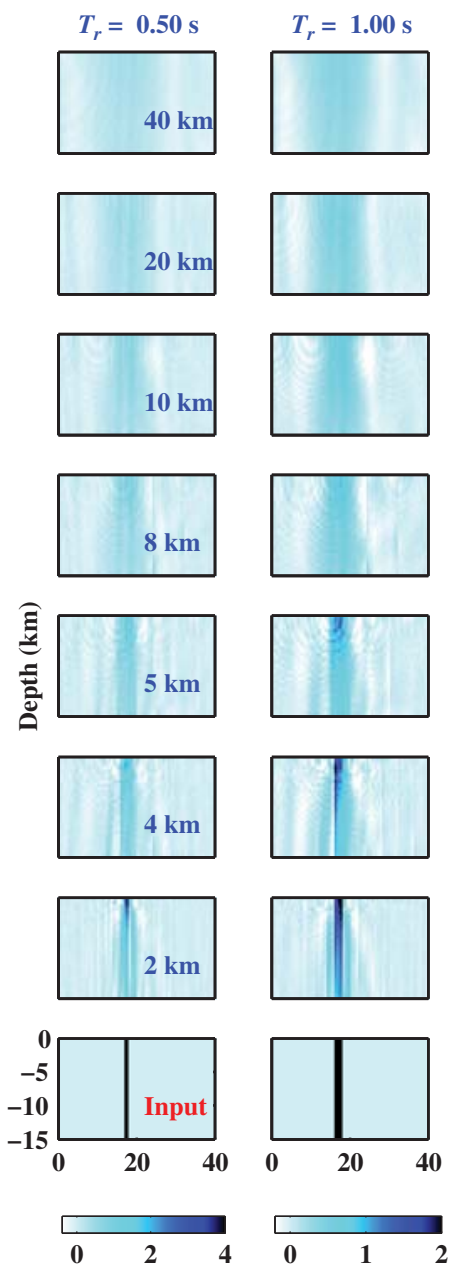
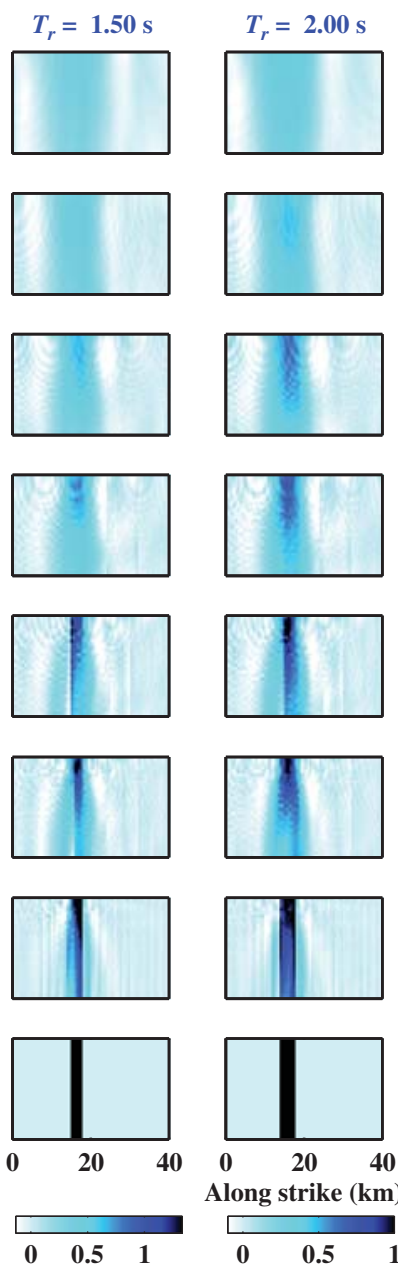
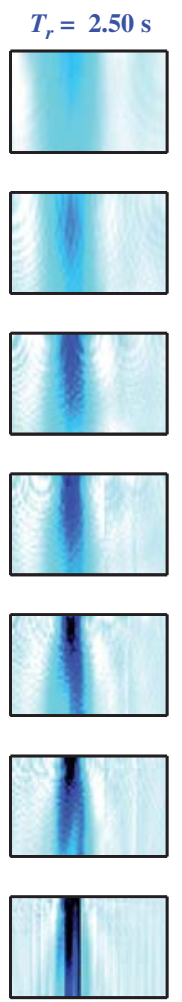

Along strike (km)

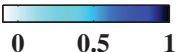

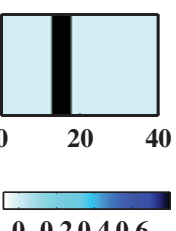

$0 \quad 0.20 .40 .6$
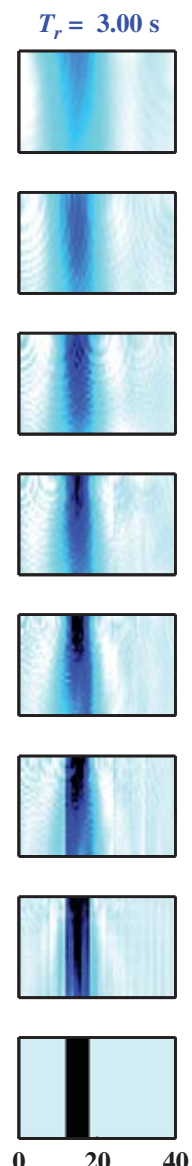

\begin{tabular}{lllll}
\hline & 0.2 & 0.4 & 0.6
\end{tabular}
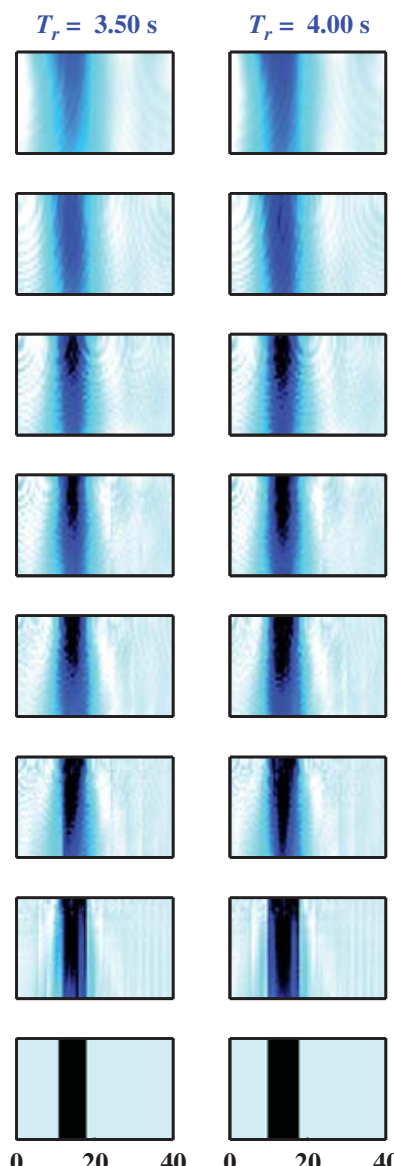

$\begin{array}{lll}0 & 0.2 & 0.4\end{array}$

$\begin{array}{lll}0 & 0.2 & 0.4\end{array}$

Figure A3. The same snapshots as in Figure 2 but after 250 iterations.

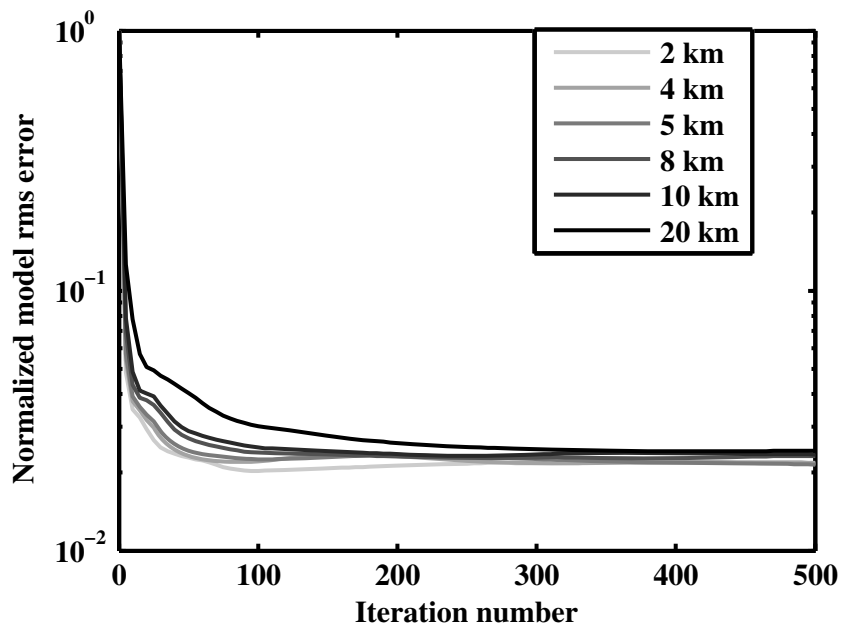

Figure A4. Normalized root mean square (rms) error of slip rate as a function of iteration number. The rms error of slip rate decreases more than $90 \%$ overall, with denser networks performing better than coarser networks. slower reduction with subsequent iterations, up to iteration 200-250 or so. However, this slower reduction is clearly important for proper recovery of the source, as demonstrated by the differences between the models at 50 and 250 iterations (Fig. A2 versus A3). After the 250th iteration, the models do not change much, consistent with the error measurement. We cannot use this error measurement for natural sources as it requires the knowledge of the actual source itself.

Instead of integrating in both space and time, integrating only in time gives the spatial variation of the slip rate rms error: $\Psi^{2}\left(\mathbf{m}, \mathbf{x}_{s}\right)=\int_{0}^{T}\left\|\mathbf{m}\left(\mathbf{x}_{s}, t\right)-\mathbf{m}^{\mathbf{0}}\left(\mathbf{x}_{s}, t\right)\right\|^{2} d t$ (Fig. A5). Just the summation over subfaults gives the temporal variation of the slip rate rms error: $\Psi^{2}(\mathbf{m}, t)=\sum_{s=1}^{N_{\text {sub-fault }}} \| \mathbf{m}\left(\mathbf{x}_{s}, t\right)-$ $\mathbf{m}^{\mathbf{0}}\left(\mathbf{x}_{s}, t\right) \|^{2}$ (Fig. A6). Figure A5 shows, as expected based on the rise-time resolution, that the rms errors for the case with the network spacings of $2 \mathrm{~km}$ are the smallest, of the order of $10^{-1}$, and systematically increase with the increasing network spacing. We also find that the spatial variation of the slip-rate rms exhibits a pattern that is related to the station spacing of the network. The temporal variation of slip rate is higher (Fig. A6) for the duration of the source (for $V_{r}=2 \mathrm{~km} / \mathrm{s}$ 

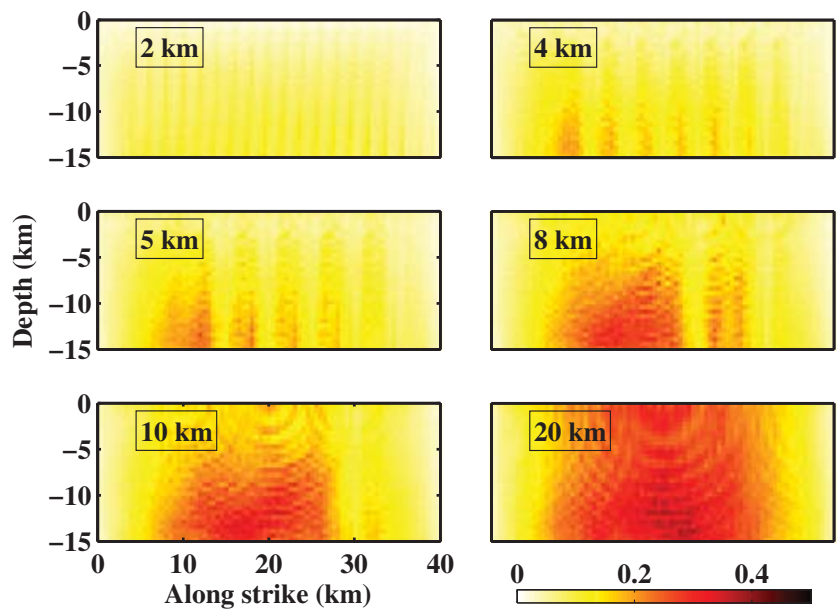

Figure A5. Variation of the normalized rms error of slip rate over the fault. Coarser networks have a higher rms error in the central region of the fault, whereas the denser networks have a uniform reduction of $\sim 90 \%$ everywhere on the fault plane.

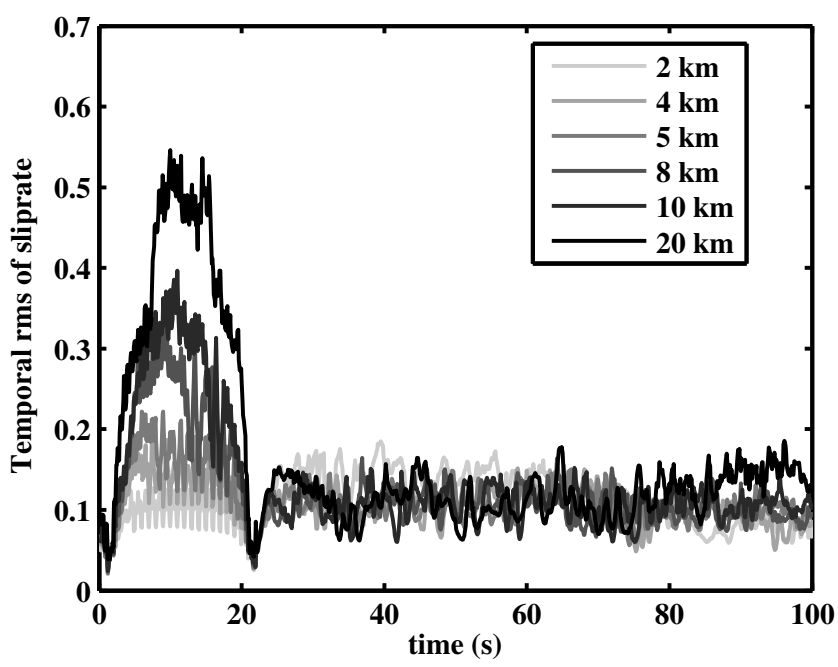

Figure A6. Normalized temporal rms error of slip rate as a function of time averaged over the entire fault plane. The densest network has only $\sim 10 \%$ rms error overall whereas the coarser networks have up to $50 \%$ rms error during the time that corresponds to the rupture duration.

and fault length of $40 \mathrm{~km}$, rupture takes $20 \mathrm{~s}$ to reach the other end of the fault) than for the rest of the simulation time. Again, as expected, the errors are smallest for the densest network of $2 \mathrm{~km}$ spacing.

The same rms error metric can also be calculated for slip in a similar fashion as it is done for slip rate. We have:

$$
\Phi^{2}(\mathbf{m})=\int_{0}^{T} \sum_{s=1}^{N_{\text {sub-fautt }}}\left\|\delta\left(\mathbf{x}_{s}, t\right)-\delta^{\mathbf{0}}\left(\mathbf{x}_{s}, t\right)\right\|^{2} d t
$$

in which $\delta$ is slip at any given iteration and $\delta^{0}$ is the input slip. The slip can be computed from the model as

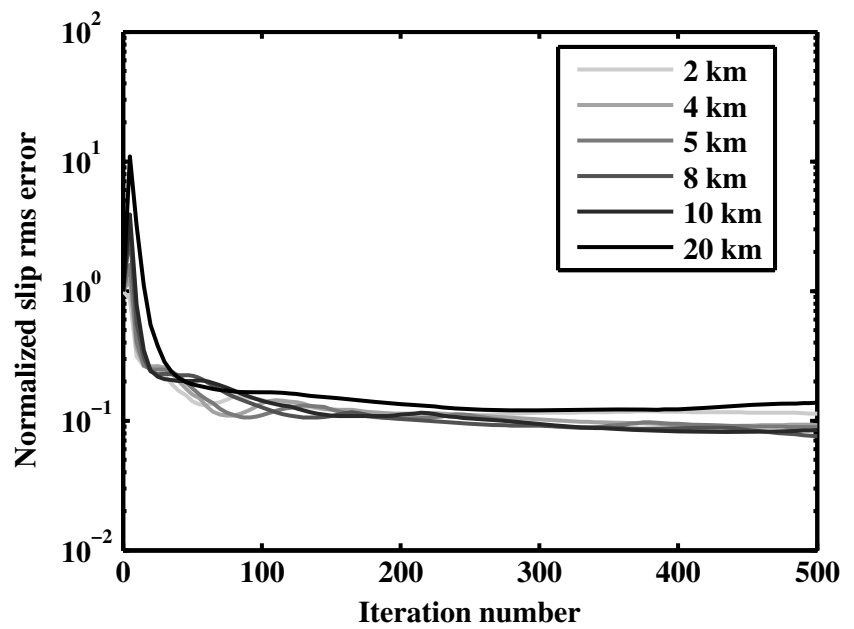

Figure A7. Normalized rms error of slip as a function of iteration number. The rms error in slip increases during the initial iterations, eventually decreasing by an order of magnitude, with denser networks giving a lower rms error than their coarser counterparts.

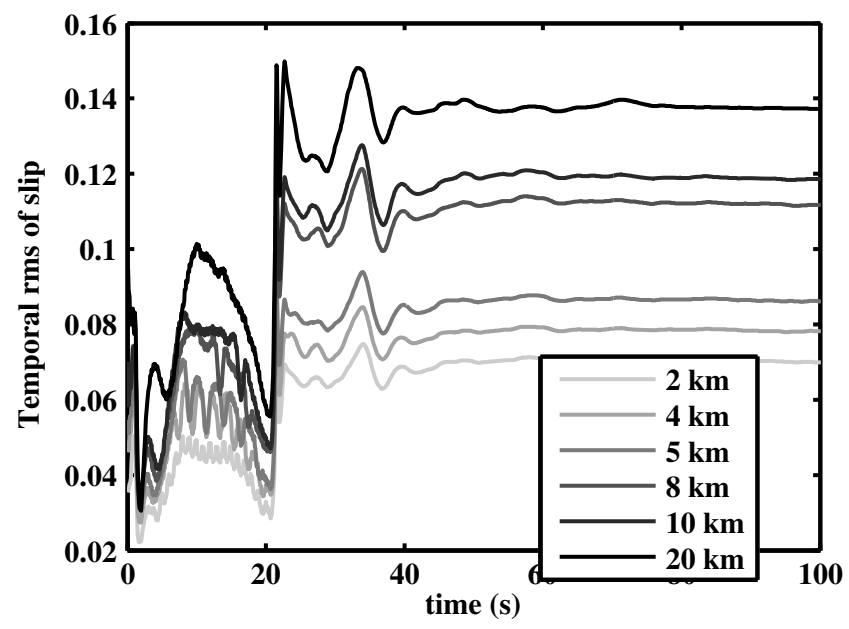

Figure A8. Normalized rms error of slip in time averaged over the entire fault plane. Errors in the final slip decrease with increasing network spacing.

$\delta=\sqrt{\delta_{x}^{2}+\delta_{z}^{2}}$, in which $\delta_{x}=\int_{0}^{t} m_{x} d t, \delta_{z}=\int_{0}^{t} m_{z} d t, m_{x}$ is the along-strike component, and $m_{z}$ is the along-dip component of slip rate. The variation of the normalized rms error of slip is shown in Figure A7. Normalization is done by dividing the rms error by the difference between the maximum and minimum values of slip. It takes more iterations for the slip rms error to stabilize (Fig. A7) than for the slip-rate rms error (Fig. A4). Summing the rms error over the subfaults gives the temporal variation $\Phi^{2}(\mathbf{m}, t)=\sum_{s=1}^{N_{\text {sub-fautt }}} \| \delta\left(\mathbf{x}_{s}, t\right)-$ $\delta^{\mathbf{0}}\left(\mathbf{x}_{s}, t\right) \|^{2}$ (Fig. A8) and integrating with respect to time gives the spatial variation $\Phi^{2}\left(\mathbf{m}, x_{s}\right)=\int_{0}^{T}\left\|\delta\left(\mathbf{x}_{s}, t\right)-\delta^{0}\left(\mathbf{x}_{s}, t\right)\right\|^{2} d t$ (Fig. A9) of the rms error of slip. Similar to the temporal pattern of the rms error of slip rate, temporal variation of the rms of slip also shows different behavior for the duration of the 

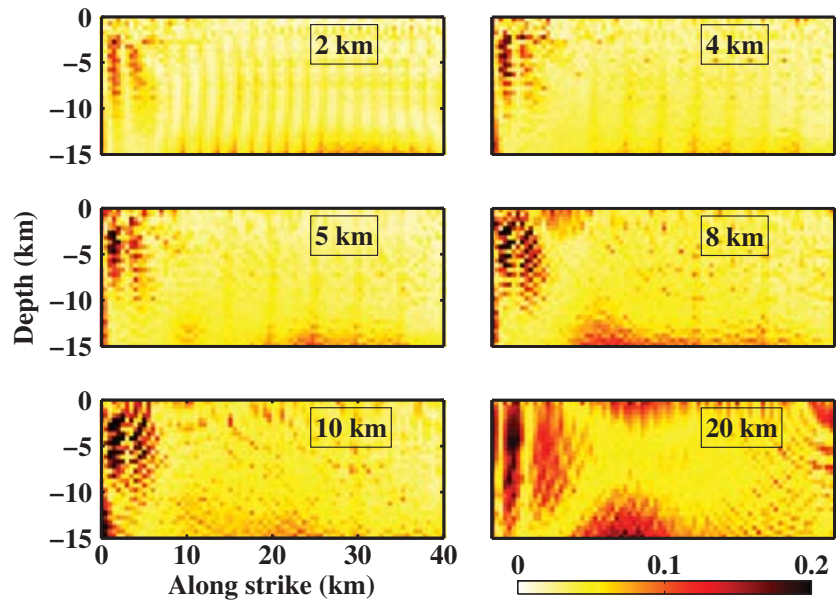

Figure A9. Variation of the normalized rms error of slip over the fault.
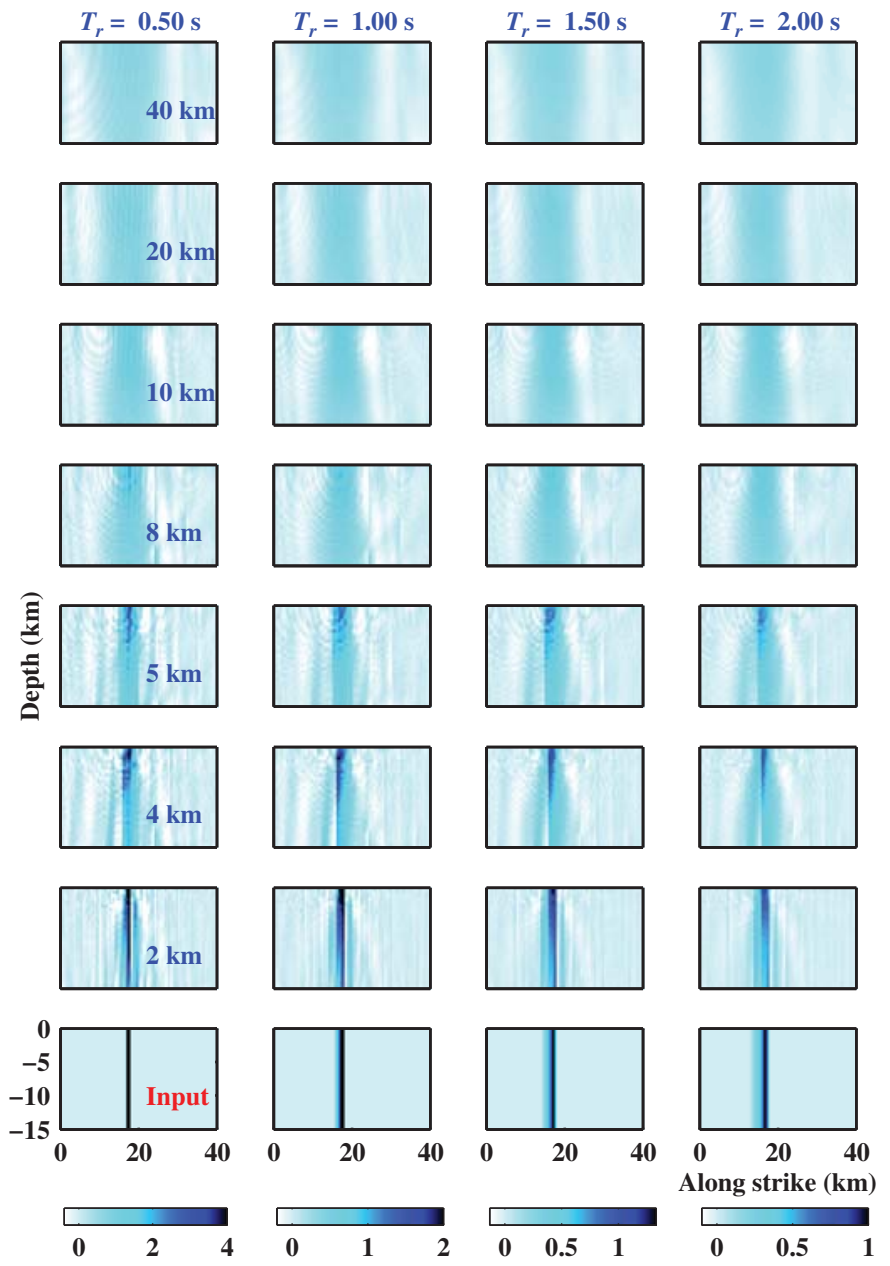
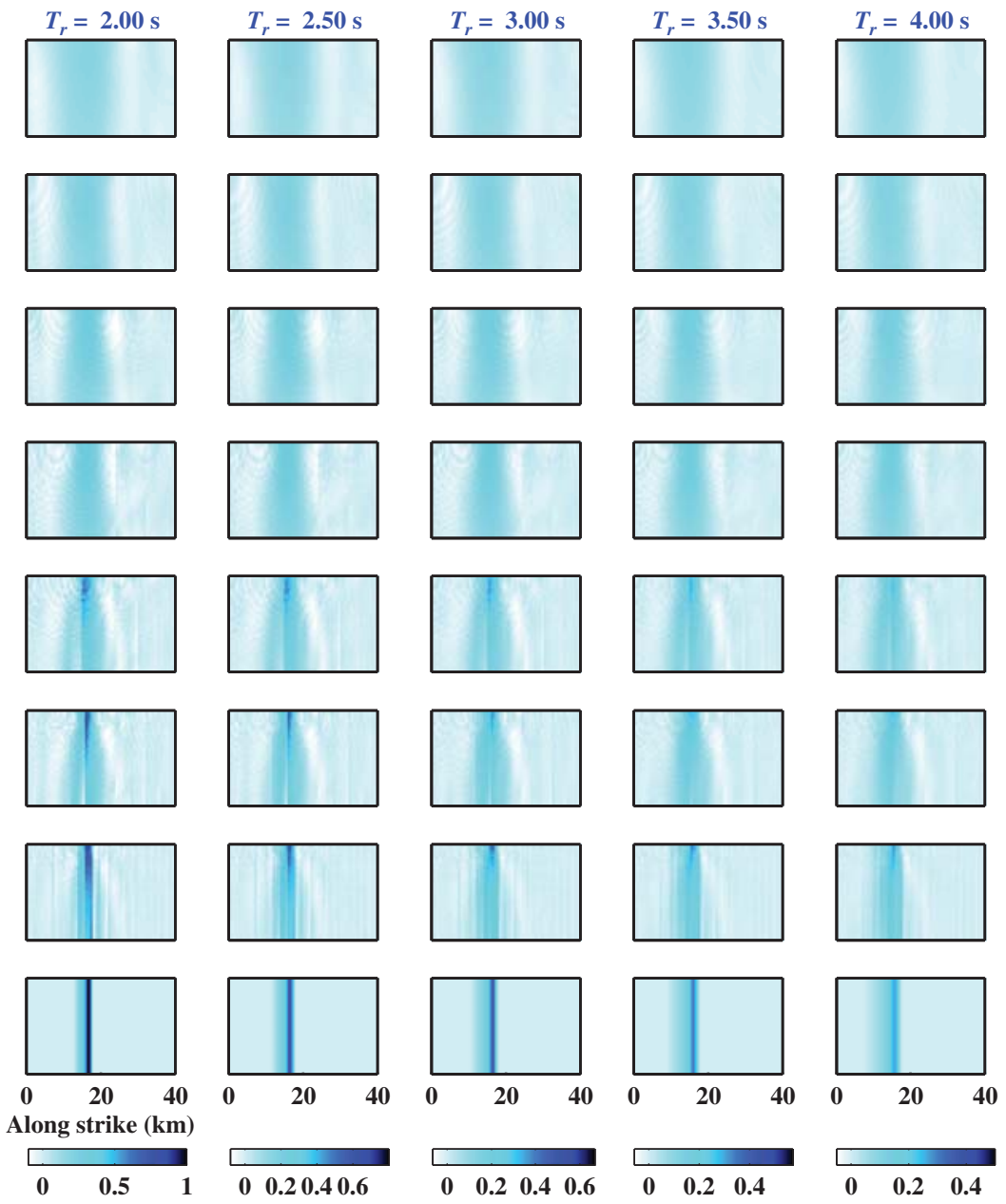

Figure B1. Representative slip rate snapshots for the input (bottom row) and inverted source models of Yoffe pulses with different rise times propagating at the subshear rupture speed of $V_{r}=2 \mathrm{~km} / \mathrm{s}$. Upper rows show inversions for different network spacings, from 40 to $2 \mathrm{~km}$. Columns correspond to different rise times, from 0.5 to $4 \mathrm{~s}$. As for the Haskell pulses, coarser networks cannot resolve shorter rise times. 

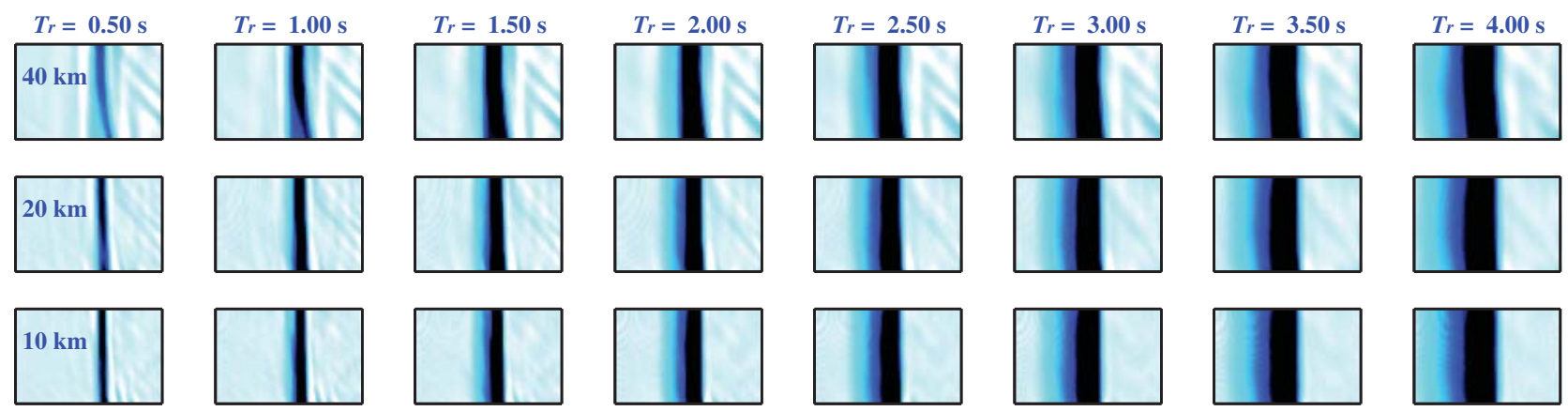

$8 \mathrm{~km}$
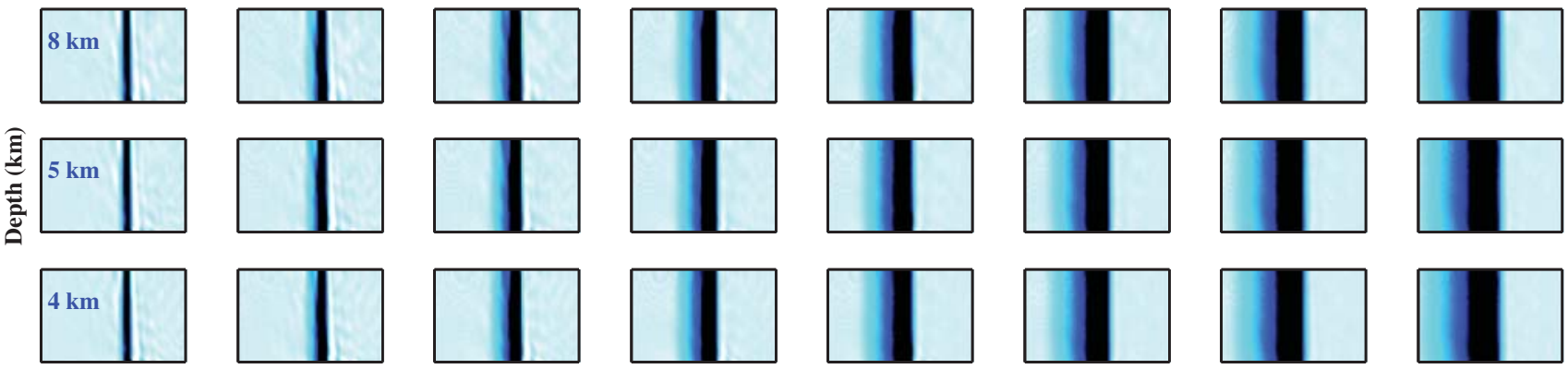

$2 \mathrm{~km}$
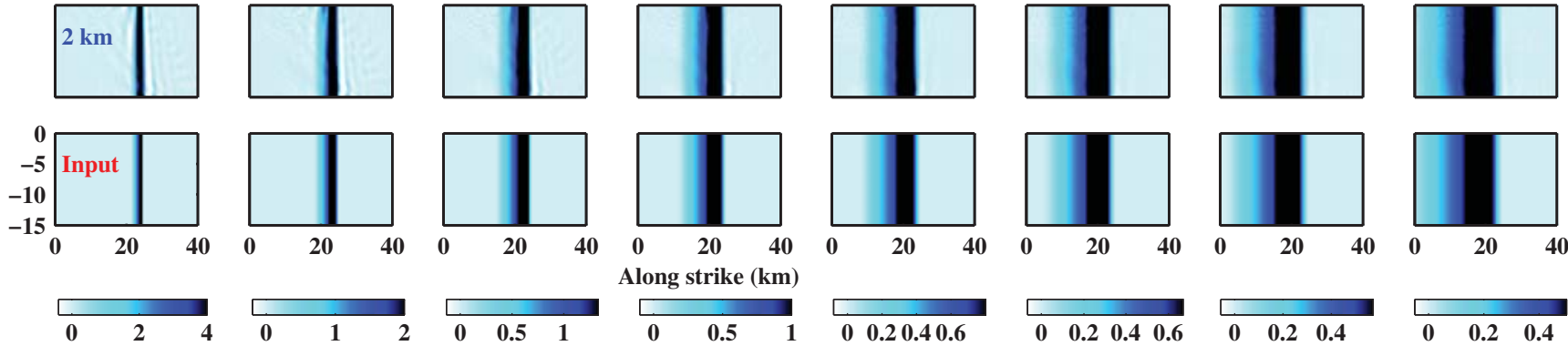

Figure B2. Same as Figure B1 but for a supershear rupture speed of $5 \mathrm{~km} / \mathrm{s}$. In the supershear regime, the rise times are well resolved by all the networks, as in the case of Haskell pulses.

(Fig. 2) pulses. Further, we illustrate the resolution for supershear ruptures (Fig. B2) by considering models with the rupture speed of $5 \mathrm{~km} / \mathrm{s}$. Figure B2 shows that, independent of the network spacing, all networks show qualitatively similar recovery, except possibly for $40 \mathrm{~km}$ network spacing.

Division of Engineering and Applied Science

California Institute of Technology

Pasadena, California 91125

somala.surendra.nadh@gmail.com

(S.N.S.)
Seismological Laboratory

California Institute of Technology

Pasadena, California 91125

ampuero@caltech.edu

$$
\text { (J.-P.A.) }
$$

Division of Geological and Planetary Sciences and Division of Engineering and Applied Science

California Institute of Technology

Pasadena, California 91125

lapusta@caltech.edu

(N.L.)

Manuscript received 12 July 2013;

Published Online 4 November 2014 